\title{
Mediation with incomplete information: Approaches to suggest potential agreements
}

\author{
Paula Sarabando (Polytechnic Institute of Viseu and INESC Coimbra) \\ Luís C. Dias (University of Coimbra, School of Economics and INESC Coimbra) \\ Rudolf Vetschera (University of Vienna)
}

\begin{abstract}
In bilateral Negotiation Analysis, the literature often considers the case of complete information. In this context, since the negotiators know the value functions of both parties, it is not difficult to calculate the Pareto efficient solutions for the negotiation. Therefore, rational negotiators can reach agreement on this frontier. However, these approaches are not applied in practice when complete information is not available. The research question of our work is "It is possible to help negotiators achieve an efficient solution in the absence of complete information regarding the different parameters of the model?". We propose to derive incomplete information about the preferences of negotiators from the statements they make and the offers they exchange during the negotiation process. We present and discuss three approaches that use this information in order to help a mediator proposing a better solution than the compromise the negotiators have reached or are close to reach.

keywords: Incomplete Information, Negotiation, Mediation, Integrative Negotiation, "Dance of the Packages"
\end{abstract}

\section{Introduction}

In negotiations it is sometimes necessary to bring in the help of a third party, in the form of a mediator or an arbitrator. A mediator is a person who should be acceptable, impartial, and neutral who does not have the power to make decisions on behalf of the negotiators. A mediator's task is to assist the negotiating parties in establishing a positive climate and reach a solution. An arbitrator is a neutral and impartial person who makes a decision in the negotiation process by comparing previous results, using justice criteria or by other methods. An arbitrator's decision may or may not be binding. In this paper, we develop new methodologies to support a mediator or arbitrator in advising negotiators (Raiffa's externally prescriptive perspective [23]). However, the methodology developed in this work can also be adapted to support one of the parties based on a description of the other party's behavior (Raiffa's asymmetrically descriptive-prescriptive perspective). 
In this study, we will be concerned with bilateral (two-party) negotiations. We consider integrative negotiations over multiple issues, which are the most likely ones to benefit from the efforts of a mediator. Integrative (or win-win) negotiation (see for example [33]) assumes the integration of resources and capabilities of parties to generate more value. This contrasts with distributive (or win-lose) negotiation where the aim is typically the division of a single good and the main concern of negotiators is to get the largest possible share of the "pie". In integrative negotiation, successful strategies include cooperation, information sharing and joint resolution of problems. Mediation and arbitration are particularly useful in integrative negotiation, since they can help negotiators to identify potential areas of improvement for both sides.

A typical form of negotiation is the "dance of packages" [23], in which offers and counter-offers are successively presented by both parties. Imagine that party 1 prepares a proposal that he finds appealing and hopes the party 2 would accept. Then, party 2 will answer with a proposal of his own. As one would expect, party 1's initial proposal might be wonderful for party 1 and unacceptable for party 2 . The counter-offers from party 2 might have the opposite characteristics. Now there are two proposals on the table, and each side describes the merits of its own offer and possibly criticizes the other. The dance of the packages proceeds by making concessions in order to seek a compromise. In a variation of this procedure, both parties might simultaneously put offers on the table.

According to Raiffa [23], integrative negotiation requires constructing and evaluating proposals covering various issues. This process entails the identification of issues to solve, the specification of the possible levels of resolution for each issue, and the specification of the scores of each possible combination of levels. Scores can be obtained through an aggregation method, e.g. the additive value model [23]. A value-based evaluation model allows each party to evaluate their potential own proposals, proposals made by the other party, and their BATNA (best alternative to a negotiated agreement).

In bilateral Negotiation Analysis, literature often considers the case of complete information. If the mediator knows the value functions of both parties, then he can calculate the set of Pareto efficient solutions and suggest an agreement from this set. A solution is Pareto efficient if it is not possible to improve the position of one party without worsening the value to one of the other parties. The choice among the Pareto efficient solutions can be based on additional criteria such as the fairness of the proposed compromise. However, in real negotiations, neither the parties nor the mediator have complete information about the preferences of all parties (see for example [17]). In many cases, parties might not even have complete information about the parameters describing their own preferences, because the assumption that parameter values can be precisely elicited is often unrealistic (see for example $[6,16,34]$ ). For a mediator in a negotiation, obtaining information about the value functions of the parties is even more difficult, since parties might strategically distort the preference information they provide [30]. To support mediators in their task, it is therefore necessary to consider methods which are based on incomplete or 
imprecise information about preferences.

In this paper we assume that the preferences of both parties can be roughly modeled by an additive value function, as in Raiffa's Negotiation Analysis [23]. However, we do not make the assumption that each party's value function is precisely known, i.e., we will not assume that the parties will indicate explicitly and exactly the parameter values that fully define their model. Although we do not assume complete information, we assume that at least some information about preferences is available. This information can come from one of two sources: it can be obtained implicitly by observing the offers or the decisions of the parties, or it can be explicitly provided by the negotiators. In both cases, we will assume that the information is provided in the form of comparisons of proposals that are implicitly or explicitly made by the parties, rather than by direct specification of utility functions, issue weights or other parameters.

Some approaches in the literature deal with incomplete information in the context of negotiation problems (see, for example, $[5,8,10,17,18]$ ). The importance of preference information is quite clearly mentioned in most of the negotiation literature. An important objective in negotiation processes is to achieve an integrative solution, which improves the position of both parties with respect to the present situation. According to the Dual Concern model $[22,28]$, these solutions can only be achieved if negotiators have a high concern about both their own preferences and the preferences of their opponents. This THis necessitates some information regarding the opponent's preferences. Typically, this information is not complete [31].

For negotiation processes with incomplete information on weights, Clímaco and Dias [5] proposed an extension of the methodology of the software VIP-G [7]. Their method is based on relaxing the set of weights each actor accepts and defining convergence paths in the weights space. Lai et al. [17] presented a model for situations where information is incomplete, the value functions are not linear and are not explicitly known. The authors refer that one of the main problems associated with multi-attribute negotiation is the difficulty of making decisions in an $n$-dimension space. To reduce this problem, a process was proposed that enables negotiators, in each period, to negotiate based on a single line, with the help of a mediator. Though it is not difficult to involve such a mediator in automated negotiations between software agents, there may exist situations where a mediator is not trusted or cannot be introduced. Thus, Lai and Sycara [18] focused on developing mechanisms for Pareto-efficient multiattribute negotiations without the presence of a mediator.

Ehtamo et al. [8] presented a class of methods called constraint proposal methods, which are interactive methods to find Pareto efficient solutions through common tangent hyperplanes. This process supports negotiations of two parties about two or more continuous issues. A mediator tries to find a hyperplane, through some reference points, so that the most preferred alternatives of both parties in this hyperplane coincide. Heikanen [10] proposed an interactive process to determine Pareto efficient solutions in negotiations with multiple parties about continuous issues, with help from a mediator. This method does not require that negotiators know the value functions of other parties or that the 
mediator knows all the value functions.

Our paper extends these existing lines of research in several directions. While most existing literature proposes one approach to deal with the problem of incomplete information, we systematically develop and compare three new approaches to support a mediator under incomplete information: the first is based on robust conclusions, the second is based on inferred approximations, and the third uses a domain-based analysis. These approaches will allow the mediator to assess how each proposal he may put forward would be received by the parties, namely if they would consider it as better than the ones they have already considered (or even accepted as a compromise), and to know which would be the most promising proposals according to some arbitration criteria. We also consider different levels of incomplete information, in particular the case where some parameters of the evaluation model are known (value functions, weights of the value functions), and the case where no parameters of the model are exactly known.

We envision two scenarios in which our methods could be applied:

1. The parties have reached a potential compromise and want to improve it.

2. The parties have not (yet) reached a compromise. There are two offers on the table, which provide different utilities to the two parties.

In the latter case, each party can at least obtain the value which it receives from the current offer made by the opponent. We therefore consider the value levels offered to the other side by each parties' proposal as the status quo in such negotiations. Our approaches therefore are applicable both to improve upon successful negotiations (to check whether the parties "left money on the table"), and to find a potential compromise in negotiations which otherwise might fail.

This paper is structured as follows. In section 2 we will present a general framework for negotiations under incomplete information. In section 3 we will propose three different approaches to suggest potential agreements. In section 4 we will present an illustrative example using the approaches presented in section 3. We will finish in section 5 with some conclusions and thoughts on future research.

\section{A Framework for negotiations under incom- plete information}

\subsection{Information levels}

In this paper, we consider several different levels of information about the negotiators' preferences over multiple issues that might be available to an outside mediator. To formally characterize this information, we chose an approach similar to [23] and assume that the true (but unknown) preferences of a negotiator can be represented by an additive value function of the form 


$$
V^{k}\left(x^{(i)}\right)=\sum_{j=1}^{n} V_{j}^{k}\left(x^{(i)}\right)=w_{1}^{k} v_{1}^{k}\left(x_{1}^{(i)}\right)+w_{2}^{k} v_{2}^{k}\left(x_{2}^{(i)}\right)+\ldots+w_{n}^{k} v_{n}^{k}\left(x_{n}^{(i)}\right)
$$

where $V_{j}^{k}\left(x^{(i)}\right)=w_{j}^{k} v_{j}^{k}\left(x_{j}^{(i)}\right), v_{j}^{k}\left(x_{j}^{(i)}\right)$ represents the value of the alternative $x^{(i)}$ (a potential compromise) in the $j^{\text {th }}$ issue and $w_{j}^{k}$ represents the scale coefficient or "weight" of the value function $v_{j}^{k}($.$) , for party k$, and $n$ represents the number of issues. Without loss of generality, we further assume that the value function is standardized so that:

$$
0 \leq w_{j}^{k} \leq 1, j=1, \ldots n \text { and } \sum_{j=1}^{n} w_{j}^{k}=1
$$

and

$$
0 \leq v_{j}^{k}\left(x^{(i)}\right) \leq 1
$$

An additive value function imposes certain restrictions on the preferences that can be represented, most notably preferential independence between the issues being considered [12, 32]. While the additive form allows us some simplifications in the models we are going to formulate (such as the use of linear programming rather than nonlinear programming), our approach does not rely very strongly on additivity of the value function. With some straightforward adaptations, it can also be extended to other forms such as bilinear or multilinear functions [12].

Function (1) allows for a classification of different types of information levels. As a benchmark, we consider the case of complete information in which all components of the value function are assumed to be known. By relaxing this assumption, we consider two possible levels of incomplete information:

1. The weights $w_{j}^{k}$ are unknown, while the values $v_{j}^{k}\left(x_{j}^{(i)}\right)$ are known.

2. Both weights and values are unknown, and only very general assumptions about the shape of the value function $v_{j}^{k}\left(x^{(i)}\right)$ are made.

In case 2 , we restrict possible value functions by a lower and an upper bound. If we can exclude increasing marginal values (which is reasonable and can easily be assessed by asking simple questions to each party) the lower bound will be formed by the linear function:

$$
v^{l i n}\left(x_{j}^{(i)}\right)=\frac{x_{j}-\underline{x_{j}}}{\overline{x_{j}}-\underline{x_{j}}}
$$

where $\overline{x_{j}}$ and $x_{j}$ represent the best and worst possible outcome in attribute $x_{j}$, respectively. The upper bound will be formed by a concave value function:

$$
v^{c o n}\left(x_{j}^{(i)}\right)=a+b\left(-e^{-c * x_{j}^{(i)}}\right)
$$


where parameters $a$ and $b$ are chosen to scale the function to values between zero and one, and parameter $c$ determines the degree of concavity of the function. Values are thus restricted to $v^{l i n}\left(x_{j}^{(i)}\right) \leq \hat{v}\left(x_{j}^{(i)}\right) \leq v^{\text {con }}\left(x_{j}^{(i)}\right)$, where we use $\hat{v}$ to indicate that this is an approximation of the unknown true value. For example, in Figure 1 we would assume that $m \leq \hat{v}_{\text {price }}(11) \leq M$. It should be noted that utility values are only assumed to lie in the interval between the linear and the concave function as shown in Figure 1. We do not assume that the "true" value function itself has a particular shape or functional form.

Figure 1: Shape of a value function of the issue price (for a seller).

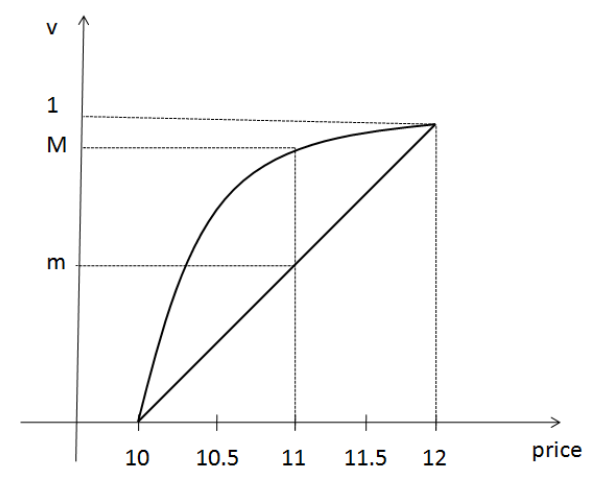

\subsection{Representation of incomplete information}

In the two cases outlined above, the mediator is not necessarily completely ignorant about the weights and/or values, but might be able to extract at least some information about them. Such information can be obtained in two ways: (i) it can explicitly be provided by the negotiators, or (ii) it can be inferred from observing their behavior during the process of the negotiation, in particular from the offers that each of them makes and their reactions to offers from the opponent.

In both cases, the information obtained by the mediator is most likely in the form of statements of preference or indifference between alternatives, where each alternative is characterized by a value for each issue. If information is directly provided by the negotiators, the mediator could ask negotiators whether they would consider another alternative to be about as good as a proposed alternative. Whenever the mediator makes a proposal, he could also ask if this proposal is indeed better than an offer already on the table, thus inferring the direction of preference between these two alternatives.

In a concession-based negotiation process as represented by the "dance of packages", preferences between alternatives can also be inferred from the offers made by negotiators during the process [31]. For instance, in a scenario 
where the negotiators have already reached a tentative compromise and wish to improve upon it, one can safely assume that a negotiator will prefer that compromise to all other offers made by the opponent during the negotiation. Otherwise, it would in most cases be possible to revert to that previous offer from the opponent (which the opponent could hardly reject, since it was him who originally proposed it). Furthermore, in a dance of packages negotiation process, negotiators typically start with offers very favorable to themselves and then successively make concessions in the course of the negotiation. Thus we can assume that a negotiator prefers all offers made by himself to the compromise and also prefers his earlier offers to the offers he made later in the process. From transitivity, it also follows that a negotiator will prefer all offers made by himself to all offers made by the opponent. This last condition can also be utilized if no compromise has been reached (yet).

Information about preferences of negotiators will therefore be available in the form of statements of preference or indifference between alternatives. Assuming an additive value function, the statement that alternative $x^{(1)}$ is preferred to alternative $x^{(2)}$ can be represented by the condition (see, e.g., [11, 31]):

$$
\sum_{j=1}^{n} V_{j}^{k}\left(x_{j}^{(1)}\right) \geq \sum_{j=1}^{n} V_{j}^{k}\left(x_{j}^{(2)}\right),
$$

while a statement of indifference can be represented by the constraint

$$
\left|\sum_{j=1}^{n} V_{j}^{k}\left(x_{j}^{(1)}\right)-\sum_{j=1}^{n} V_{j}^{k}\left(x_{j}^{(2)}\right)\right| \leq \epsilon
$$

where $\epsilon$ is a suitably small tolerance value.

The specification of $V_{j}^{k}$ depends on the information level being considered. For the case of unknown weights and known values, it is defined as

$$
V_{j}^{k}\left(x_{j}^{(i)}\right)=w_{j}^{k} v_{j}^{k}\left(x_{j}^{(i)}\right)
$$

i.e. the unknown weight is combined with the known value function of negotiator $k$. In this case, the constraints are linear in the weights and define a feasible set of weights $W_{k}$ (a polytope) which can be considered as the set of possible preference parameters of negotiator $k$.

In the second case, with unknown weights and unknown values, the values for $V_{j}^{k}\left(x_{j}^{(i)}\right)$ can directly be used as variables in the model, as in [9]. Let $s_{j}$ denote the number of different values for $x_{j}^{(i)}$ considering all the potential alternatives. Let us define a vector of $s_{1}+\ldots+s_{n}$ variables $v_{i, j}^{k}=V_{j}^{k}\left(x_{j}^{(i)}\right)$. These variables can be used in constraints of type (6) and (7). Furthermore, if $\overline{x_{j}^{k}}$ represents the best possible outcome in attribute $x_{j}$ for party $k$, then considering $v_{j}^{k}\left(\overline{x_{j}^{k}}\right)=1$ we will have $V_{j}^{k}\left(\overline{x_{j}^{k}}\right)=w_{j}^{k}$. 
If we assume that values are ordered in decreasing order of preference, i.e. that $v_{1, j}^{k}$ represents $V_{j}^{k}\left(\overline{x_{j}^{k}}\right)$, we can express (2) as:

$$
1 \geq w_{j}^{k}=v_{1, j}^{k}>v_{2, j}^{k}>\ldots>v_{s_{j}, j}^{k}=0 \text { and } \sum_{j=1}^{n} v_{1, j}^{k}=1 .
$$

Therefore, we are dealing with linear problems even in the case where both the weights and the values are unknown.

If the value function for each attribute is assumed to be known, the constraints (6), (7), and (2) (plus possibly other ones) define a polytope $W_{k}$ of admissible weights. In the case of unknown value functions, the constraints (6), (7), and (9) (plus possibly other ones) define a feasible set of values we denote by $M_{k}$ (also a polytope). In either case, the polytope can be considered as the set of possible preference parameters of negotiator $k$. It should be noted that we assume here that all actions of a negotiator, and all preference statements provided by a negotiator, are consistent with a true value function of the form (1). If this is not the case, and constraints derived from the negotiator's choices contradict each other, these sets might become empty.

In the next section will use the general notation $(w, v) \in\left(W_{k}, M_{k}\right)$ to indicate that:

$$
(w, v) \in\left(W_{k}, M_{k}\right) \Leftrightarrow \begin{cases}\left(w_{1}^{k}, \ldots, w_{n}^{k}\right) \in W_{k} & \text { if } v_{j}^{k}(.) \text { is known. } \\ \left(v_{1,1}^{k}, \ldots, v_{s_{1}, 1}^{k}, \ldots, v_{s_{n}, n}^{k}\right) \in M_{k} & \text { if } v_{j}^{k}(.) \text { is unknown. }\end{cases}
$$

\subsection{Criteria for selecting alternative solutions}

Using information of one of the types presented above, the mediator can suggest one or several alternative solutions to the negotiators. Proposals from the mediator should have a high chance of being accepted by both parties, and also fulfill additional mediation criteria. We start by defining these criteria, and will present three different approaches to obtain such proposals in the next section.

The dominance criterion is a natural starting point in selecting proposals. If only this criterion is used, the mediator could identify all alternatives which dominate the currently proposed compromise $x^{(c)}$ or the status quo of the negotiation. In negotiations which have not yet reached a compromise, the status quo consist of the utility values which offers from both sides provide to the recipient of the offer. Conversely, alternatives which are dominated by the proposed compromise or by the status quo can be eliminated from further consideration.

Formally, let $x^{(r)}$ denote the reference (or reservation) point below which the negotiators will not accept any alternative. If a compromise has been reached, then $x^{(r)}=x^{(c)}$. If a compromise has not been reached and the two last offers on the table are $x^{\left(o_{1}\right)}$ (offered by negotiator 1) and $x^{\left(o_{2}\right)}$ (offered by negotiator 2), then $x^{(r)}$ will refer to the point $\left(V^{1}\left(x^{\left(o_{2}\right)}\right), V^{2}\left(x^{\left(o_{1}\right)}\right)\right)$ in value space. Although 
$\left(V^{1}\left(x^{\left(o_{2}\right)}\right), V^{2}\left(x^{\left(o_{1}\right)}\right)\right)$ is a fictitious alternative, it is not an utopian alternative which is better than any existing one. By construction, this point is dominated by $x^{\left(o_{1}\right)}$ and $x^{\left(o_{2}\right)}$, so it makes sense to search for other alternatives dominating it.

The alternatives to be proposed by the mediator should, for both negotiators, be better than $x^{(r)}$. Since preference information is incomplete, one can distinguish here between alternatives which surely dominate $x^{(r)}$ (i.e. which are better for both parties under all preference parameters still considered possible), alternatives which possibly dominate $x^{(r)}$ (i.e. which are better for both parties for at least one vector of preference parameters for each party), and alternatives that cannot dominate $x^{(r)}$. In the last case, for at least one party, there is no vector of preference parameters for which that alternative is better than $x^{(r)}$.

As a second criterion, the alternatives to be proposed should also be Pareto efficient concerning the value they yield to each party. Once again, under incomplete information, we can distinguish between alternatives that are surely efficient, alternatives that are possibly efficient, and alternatives that cannot be efficient (because they are surely dominated by another alternative).

If the mediator wants to present only one (or a small number) of alternatives to the parties, additional criteria can be used to guide this selection. Several such criteria can be developed, depending on whether the mediator is more interested in finding an efficient solution (which maximizes total value creation) or an equitable solution (which tries to balance the interests of the parties involved). In this paper, we consider the following mediation criteria [23]:

1. The max-sum criterion, which maximizes the sum of values of both parties and thus selects the alternative which is best according to total efficiency.

2. The max-min PoP criterion, which maximizes the minimum payoff, i.e. the payoff to the negotiator who receives the lowest payoff from the negotiation result. To make payoffs comparable between negotiators, they are standardized within the possible range by calculating the Proportion of Potential (PoP).

Thus, the max-sum criterion selects the alternative which maximizes

$$
V^{1}\left(x^{(i)}\right)+V^{2}\left(x^{(i)}\right)
$$

and the max-min PoP criterion maximizes

$$
\min _{k} \frac{V^{k}\left(x^{(i)}\right)-V_{\min }^{k}}{V_{\max }^{k}-V_{\min }^{k}}
$$

where $V_{\max }^{k}$ is the best payoff that negotiator $k$ could achieve considering the set of alternatives being considered, and $V_{\min }^{k}$ is a lower limit on the payoffs considered for negotiator $k$ for the same set of alternatives. To ensure acceptability of the proposal, we only consider alternatives which are at least as good as $x^{(r)}$ for both parties when maximizing the criteria. 
Naturally, other mediation criteria could be used, e.g., maximizing the product of values exceeding $x^{(r)}$, which is equivalent to the Nash bargaining solution using $x^{(r)}$ as a disagreement point. Although generalization to those other criteria is straightforward, we will restrict our analysis in this paper to the max-sum criterion and the max-min PoP criterion, because they lead to linear programming models, while other criteria would require nonlinear models.

Considering incomplete information, we can again distinguish different classes of alternatives: alternatives that are surely optimal for a criterion (i.e. maximize that criterion for all possible preference parameters), and alternatives that are potentially optimal (i.e. maximize the criterion for at least one vector of possible preference parameters, while for some other possible parameter values the maximum is obtained at another alternative). Alternatives are called surely non-optimal if no preference parameter $(w, v) \in\left(W_{k}, M_{k}\right)$ exists at which the alternative maximizes the criterion under consideration.

\section{Approaches to suggest potential agreements}

\subsection{Extreme parameters approach}

As a first approach, we formulate optimization models to identify alternatives for which one of the mediator's requirements described in the previous section surely holds, or surely does not hold. An alternative surely meets a certain requirement if that requirement is fulfilled for all possible parameter vectors. Similarly, an alternative surely does not meet a requirement if that requirement is not fulfilled for any of the possible parameter vectors. This analysis is only concerned with one single alternative at a time, other alternatives might exist that also fulfill the requirement. We call this first method the "extreme parameters" approach, because we are looking for parameter values which lie on the boundary of the feasible set, leading to extreme value differences.

To find out whether an alternative is surely better or surely worse than the reference, a Linear Program (LP) can be solved. Recall that $V^{k}\left(x^{(i)}\right)$ is the value of alternative $x^{(i)}$ for negotiator $k(k=1,2)$. Let $m_{i j}^{k}$ denote the solution of the following LP:

$$
\begin{aligned}
& \max \left\{V^{k}\left(x^{(i)}\right)-V^{k}\left(x^{(j)}\right)\right\} \\
& (w, v) \in\left(W_{k}, M_{k}\right)
\end{aligned}
$$

Whenever $m_{i j}^{k}<0$, there is no possible combination of parameters which would make alternative $x^{(i)}$ at least as good as $x^{(j)}$ for negotiator $k$, thus we can say that $x^{(j)}$ is surely better than $x^{(i)}$ (or $x^{(i)}$ is surely worse than $x^{(j)}$ ) with respect to the available information about negotiator $k$ 's preferences.

Given the sets of feasible parameter values $\left(W_{1}, M_{1}\right)$ and $\left(W_{2}, M_{2}\right)$, it is possible to determine, for each negotiator, which alternatives are surely better than the reference point $x^{(r)}$ and which alternatives are surely worse than the reference point. The mediator would like to propose an alternative $x^{(i)}$ such that $m_{r i}^{1}<0$ and $m_{r i}^{2}<0$. The problem is that it can happen that there are 
no alternatives that are surely better than the reference for both negotiators. Nevertheless, this approach is a good starting point: if there are alternatives that are surely worse than the reference for one of the negotiators, then the mediator can discard these alternatives, i.e., we can eliminate the alternatives $x^{(i)}$ for which $m_{i r}^{1}<0$ or $m_{i r}^{2}<0$. These calculations are analogous to those proposed by Dias and Clímaco [6] to obtain binary robust conclusions. Hence, only the alternatives that are potentially at least as good as the reference for both negotiators are candidates to be proposed to them.

The LP (13) can also be used to compare any other pairs of alternatives, besides pairs containing the reference $x^{(r)}$. This allows to check for Pareto

efficiency. For a pair $\left(x^{(i)}, x^{(j)}\right)$, if $m_{j i}^{1}<0$ and $m_{j i}^{2}<0$, then $x^{(j)}$ is surely worse than $x^{(i)}$ for both negotiators and hence $x^{(j)}$ is surely not Pareto efficient. Thus it can also be discarded.

Let $P$ denote the index set of the remaining candidate alternatives, after discarding alternatives surely worse than the reference point for any of the negotiators and alternatives surely not belonging to the Pareto frontier. To discriminate between alternatives in $P$, the mediator might also try to identify which ones can be potentially optimal according to a mediation criterion. For the max-sum criterion the following LP is solved for each alternative $x^{(i)} \in P$ :

$$
\begin{aligned}
& \max \delta \\
& V^{1}\left(x^{(i)}\right)+V^{\prime 2}\left(x^{(i)}\right)-\left[V^{1}\left(x^{(j)}\right)+V^{\prime 2}\left(x^{(j)}\right)\right]-\delta \geq 0, \forall j \in P, j \neq i \\
& (w, v) \in\left(W_{1}, M_{1}\right) \\
& \left(w^{\prime}, v^{\prime}\right) \in\left(W_{2}, M_{2}\right) \\
& \delta \text { free }
\end{aligned}
$$

If this LP yields $\delta \geq 0$ at the optimal solution, then $x^{(i)}$ is potentially optimal according to the max-sum criterion; otherwise, it cannot be the best alternative according to that criterion. Furthermore, if an alternative is the only one for which a solution with $\delta>0$ is obtained, that alternative is surely optimal. Let us note that if we tried to maximize the sum of the values, this would not lead to acceptable results (for more details see [25]). To perform a similar analysis considering another mediation criteria requires introducing binary variables (for the criterion of maximizing the minimum $\mathrm{PoP}$ ) or nonlinear programming (for criteria involving products).

\subsection{Central parameters approach}

A second approach the mediator might use to find good potential alternatives consists in inferring a representative combination of parameter values from $\left(W_{1}, M_{1}\right)$ and $\left(W_{2}, M_{2}\right)$. Using these surrogate parameter values, the mediator can identify alternatives that are better than the reference point for both negotiators, are efficient, or are optimal according to a mediation criterion. Of course, the conclusions that hold for such a surrogate parameter vector do not necessarily hold for the true parameter values that would be obtained by a 
thorough and explicit utility elicitation process. Nevertheless, studies in the context of additive value functions (e.g., $[1,24]$ ) show that using a combination of parameter values that is central to the feasible set yields good approximations. The more information the mediator has, in terms of constraints to the parameter values, the more accurate this approximation will be.

One possible approach to find a central combination of parameter values is to solve a LP of the max-min type in order to find a point such that the smallest slack in a constraint of the form (6) is as large as possible. This is an approach used for inferring parameters of multicriteria aggregation approaches (e.g., $[2,11,21])$. Let $A_{k}$ denote a coefficient matrix and let $b_{k}$ denote a righthand side vector such that $(w, v) \in\left(W_{k}, M_{k}\right)$ if and only if $A_{k} \cdot(w, v) \leq b_{k}$. Let $s_{k}$ be a vector containing one constant per constraint, equal to 1 if the constraint is of type (6) and equal to 0 otherwise. The following LP can then be used to infer a central parameter vector with respect to the inequality preference statements, for $k \in\{1,2\}$ :

$$
\begin{aligned}
& \max \Delta^{k} \\
& A_{k} \cdot(w, v)+s_{k} \Delta^{k} \leq b_{k}
\end{aligned}
$$

The variables of this problem are the scalar $\Delta^{k}$, which represents the smallest slack to be maximized, the weights, and possibly the values. The optimal solution can be considered to be the "safest" vector, which is as far as possible from any boundary. Due to this point, our objective is to maximize the slack. Note that all constraints are formulated in terms of the multi-attribute value function, which is scaled between zero and one, and thus have a comparable magnitude. This makes it possible to compare deviations across constraints without further rescaling.

A central combination of parameter values can also be found by computing the centroid of $\left(W_{k}, M_{k}\right)$ in an exact manner or using an approximation. Exact methods exist for some types of polytopes [26]. An approximation to the centroid of any polytope can however be easily obtained using Monte-Carlo simulation, as in the computation of central weights used in the SMAA method [15].

Let $\left(w^{1}, v^{1}\right)^{*}$ denote the central parameter vector obtained for negotiator 1 , and let $\left(w^{2}, v^{2}\right)^{*}$ denote the analogous result obtained for negotiator 2. Using $\left(w^{1}, v^{1}\right)^{*}$ and $\left(w^{2}, v^{2}\right)^{*}$ as surrogate parameter values, it is possible to compute alternatives that are better than the reference point for both negotiators, which maximize the mediation criteria. In contrast to the extreme parameters approach, maximizing the minimum PoP or criteria involving products is straightforward in the central parameters approach, because it is only necessary to compute the respective objective function for each alternative using one parameter vector. In addition to the optimal alternative for the mediation criterion, the set of all other efficient solutions for the central parameter vector can also be determined easily.

Since the parameter vector used in this approach is only an approximation, it might not reflect the true preferences of negotiators. As a result, it is possible 
that a negotiator finds an alternative $x^{(i)}$ proposed by the mediator unacceptable. From such a statement, the mediator can conclude that alternative $x^{(i)}$ has a lower value than the reference point $x^{(r)}$ for negotiator $k$. This information leads to a new constraint $V^{k}\left(x^{(i)}\right)<V^{k}\left(x^{(r)}\right)$, which reduces the parameter sets $\left(W_{k}, V_{k}\right)$. Using this new and smaller polytope, new central parameters can be computed, which then can be used to generate another proposal.

\subsection{Domains approach}

The domain criterion, introduced by Starr [27], uses the volume of a region in parameter space in which an alternative remains optimal to indicate the sensitivity of a solution. The use of this criterion for multi-attribute decision problems was proposed by Charnetski and Soland [4]. SMAA methods [16] are also based on exploring the weight space in order to describe the preferences that would make each alternative the most preferred one, or that would give a certain rank for a specified alternative. The method proposed by Vetschera [31] to measure the extent to which information about the preferences is available during a negotiation is also based on the domain criterion.

Our third approach is also based on this concept and calculates the relative volume of the feasible set of parameter values for which some conditions are fulfilled. Let $S$ denote the set of feasible parameter values for the two parties given the information currently available:

$$
S=\left\{\left(w^{1}, v^{1}, w^{2}, v^{2}\right) \in\left(W_{1}, M_{1}\right) \times\left(W_{2}, M_{2}\right)\right\} .
$$

Let $S(\tilde{C})$ denote the subset of $S$ where condition $\tilde{C}$ holds:

$$
S(\tilde{C})=\left\{\left(w^{1}, v^{1}, w^{2}, v^{2}\right) \in\left(W_{1}, M_{1}\right) \times\left(W_{2}, M_{2}\right): \tilde{C} \text { is true }\right\} .
$$

Let $\operatorname{Vol}(S(\tilde{C}))$ denote the volume of set $S(\tilde{C})$ and let $\operatorname{Vol}(S)$ denote the volume of set $S$. The expression

$$
\operatorname{Vol}(S(\tilde{C})) / \operatorname{Vol}(S)
$$

then denotes the relative volume of the subset in which condition $\tilde{C}$ holds as compared to the volume of the entire feasible region. If we further assume that parameter vectors are uniformly distributed, this ratio can be interpreted as the probability that condition $\tilde{C}$ is fulfilled for any randomly drawn feasible parameter vector.

The relative volume of the parameter set in which each alternative $x^{(i)}$ is at least as good as the reference for both negotiators can be computed as

$$
\operatorname{Vol}\left(S\left(V^{1}\left(x^{(i)}\right) \geq V^{1}\left(x^{(r)}\right) \wedge V^{2}\left(x^{(i)}\right) \geq V^{2}\left(x^{(r)}\right)\right)\right) / \operatorname{Vol}(S) .
$$

Note that this relative volume is equal to zero for alternatives that are surely worse than $x^{(r)}$, and is equal to one for alternatives that are surely better than the reference point. This approach therefore complements the extreme values 
approach by providing additional information about alternatives which are between the two extreme cases of being surely better or surely worse than the reference point. It indicates the probability that, given the preference information collected so far from the negotiators, both negotiators will prefer alternative $x^{(i)}$ over the reference value.

In a similar way, the relative volume of the parameter set in which each alternative is Pareto efficient is given by: $\operatorname{Vol}\left(S\left(x^{(i)}\right.\right.$ is efficient $\left.)\right) / \operatorname{Vol}(S)$.

The same approach can also be applied to the mediation criteria. The relative volume of the subset of parameter space where each alternative $x^{(i)}$ is optimal according to the different mediation criteria (maximizing the sum of the values, maximizing the minimal PoP, etc.) can in general be written as $\operatorname{Vol}\left(S\left(x^{(i)}\right.\right.$ is optimal $\left.)\right) / \operatorname{Vol}(S)$. For the sum of values criterion this relative volume is:

$$
\operatorname{Vol}\left(S\left(V^{1}\left(x^{(i)}\right)+V^{2}\left(x^{(i)}\right) \geq V^{1}\left(x^{(j)}\right)+V^{2}\left(x^{(j)}\right), \forall j \neq i\right)\right) / \operatorname{Vol}(S) .
$$

These volumes can again be interpreted as probabilities. Therefore, they provide a probability distribution across alternatives indicating the possible optima. Alternatives having zero probability will definitely not be optimal, while alternatives with a high probability of being optimal can be considered as robust solutions.

The domains approach can also be used interactively in a similar way as the central parameters approach. If a negotiator does not accept one alternative, it is possible to redefine $S$ by introducing a new constraint to eliminate this alternative and calculate again the domain volumes.

As the mediator should be informed of the relative volumes of many different results, we suggest to use Monte-Carlo simulation to approximate volumes. Exact methods for computing volumes also exist (see, e.g., [19, 20, 29]), but are more computationally demanding and can be used only for one question at a time.

The simulation generates a large number $n_{i t e r}$ of random instances of the two negotiators's parameter values satisfying all the constraints. For each vector, all properties $\tilde{C}$ of interest can be evaluated simultaneously, i.e. which alternatives are better than the reference $x^{(r)}$ for both of the negotiators, which alternatives are efficient, and which alternative is the best one according to each mediation criterion (as it is also possible to analyze several mediation criteria simultaneously). Considering the results for all these instances, it is possible to indicate, for each alternative $x^{(i)}$, the proportion of instances where each of the above mentioned conditions was verified for that particular alternative. In order to allow for (relative) volumes to be interpreted as probabilities, a uniform distribution of parameter vectors must be used for the simulations. In the experiments described in the next section, scaling weights were generated according to an uniform distribution using the process described in [3].

When we interpret the volumes as probabilities, it might also be interesting to compute conditional probabilities, e.g., the probability that an alternative 
is optimal for a mediation criterion under the condition that it is better than the reference point and efficient. Such conditional probabilities can also be obtained from the simulation by recording the number of instances in which both conditions are fulfilled and calculating

$$
p(\tilde{C} \mid \tilde{D})=p(\tilde{C} \& \tilde{D}) / p(\tilde{D})
$$

where $\tilde{C}$ and $\tilde{D}$ represent the two conditions to be analyzed.

\subsection{Comparison of the three approaches}

\subsubsection{Properties}

In the preceding subsections, we proposed three approaches to support a mediator who observes a dance of the packages with incomplete information. In this subsection we discuss properties of the presented approaches.

Since they are based on incomplete information, the models might mislead the mediator to propose unsuitable alternatives. The first property we analyze directly deals with the question whether an approach will support statements which are not true in view of the actual preferences of the negotiators (e.g. whether it is possible that an alternative will be indicated to be better than the reference value for both negotiators, while in reality it is not).

Our methods represent different ways of handling uncertainty about preferences. The domains approach in a way relates to decision criteria under risk like the expected value, which explicitly take into account probabilities. The extreme parameters approach could be compared to a pessimistic min-max criterion, which only looks at the baseline which can be obtained under any circumstances.

Taking the analogy to statistical decisions under risk a step further, two kinds of errors can be made when outcomes are uncertain: on one hand, an alternative can be indicated as optimal or as better than another alternative while in reality it is not, whilst on the other hand, the method might fail to identify an alternative which is good in reality. All methods might lead to the second kind of error. We therefore focus our discussion on the first kind of error, declaring an alternative erroneously as optimal.

The extreme parameters approach will compute exactly which alternatives are surely better, which alternatives are possibly better, which alternatives are surely efficient or surely not efficient, and will determine whether there exists an optimal alternative for all parameter values and which alternatives might be optimal. If the information provided by the negotiators is consistent (which we are assuming) it is therefore not possible to obtain wrong results using the extreme parameters approach.

The central parameters approach makes statements about alternatives assuming a central parameter vector. However, the central vector is just an approximation, which can be a rather coarse one if information is scarce. Hence, there is no guarantee that the supposedly better alternatives will really have 
higher value than the reference point, or any of the other statements made about alternatives will really hold for the true preference parameters.

The domains approach will compute the probabilities that each alternative is better than the reference point for both negotiators simultaneously, the probabilities that each alternative is efficient, and the probabilities of each alternative being optimal. The conditions with probability equal to 0 or to 1 will correspond to conditions that "surely" do not hold or to conditions that "surely" hold, respectively, and thus correspond to exact information like the extreme parameters approach. In these cases, the domains approach will also never be misleading. However, when some property holds with a probability strictly between zero and one, there is the possibility that the statement might be true or false for the true preference parameters. In particular, this approach might be misleading to the mediator if different probabilities are attached to different alternatives. For example, the mediator might be tempted to propose an alternative which has the highest probability of being optimal according to some arbitration criterion, while according to the true preference parameters, another alternative (for which only a low probability is indicated) is optimal.

Therefore, according to the possibility of providing misleading results, we rank the extreme parameters approach first, followed by the domains approach, and the central parameters approach comes last.

When information is incomplete, there is also the possibility to obtain additional information to improve the quality of results. One would wish that this additional information indeed improves the quality of results. Additional information would be misleading if, without the additional information, a method delivers a correct result (e.g. indicates the truly optimal alternative to be the best one according to some arbitration criterion), while after adding more information, the method delivers a different - and thus wrong - result.

For simplicity, we analyze this property only for the case of unknown weights, but results can easily be generalized to the other cases. Consider some statement which the mediator wants to verify, e.g. that alternative $x^{(i)}$ is better than the reference value. The situation before receiving additional information is depicted in Figure 2. The polygon represents the set of all weight vectors which are still considered as possible given the information which the mediator has received so far. Let the true weight vector (which is unknown to the mediator) be located at point $\mathbf{T}$. The left part of the polygon represents all parameter vectors for which the statement under consideration would be true, the right part those parameter vectors for which the statement is false. Since the true parameter vector is located in the left part, the statement is true in reality.

The three approaches will process this situation in the following way:

- Since the set of feasible weight vectors contains both vectors for which the statement is true and some vectors for which it is false, the extreme parameters approach will indicate that the statement is possibly true (e.g. alternative $x^{(i)}$ is possibly better than the reference level).

- In the central parameters approach, the mid-point $\mathbf{M}$ of the polygon is 
Figure 2: Original set of feasible parameters

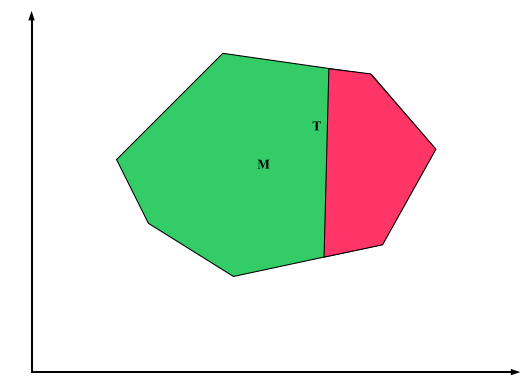

used for evaluation. At this point, the statement is true, so the central parameters approach will indicate the statement to be true.

- In the domains approach, the left area indicates the probability that the statement is true, the right area the probability that the statement is false. The domains approach will therefore indicate that the statement has a probability well over fifty percent of being true.

Now the mediator obtains additional information about the preferences of a negotiator, which leads to an additional constraint represented by a new line in Figure 3.

Figure 3: Changed set of feasible parameters

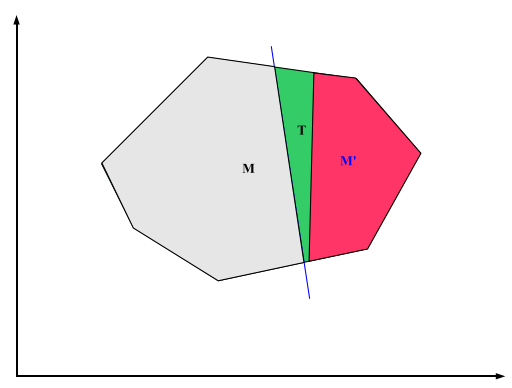

The three approaches will process this additional information in the following way:

- Since the set of feasible parameter vectors still contains elements for which the statement is true and elements for which the statement is false, the extreme parameters approach will still indicate that the statement is potentially true. In fact, since any additional constraint that is based on the correct preferences of a negotiator will retain the true parameter vector in 
the feasible set, the extreme parameters approach will always indicate at least that the statement is possibly true. If the constraint eliminates all parameter vectors for which the statement is false, the statement would even be indicated as surely true.

- In the central parameters approach, point $\mathbf{M}^{\prime}$ will now be used as parameter vector. For this point, the statement is false, so this approach will now incorrectly indicate that the statement is false.

- The domain approach will now indicate a much higher probability for the statement to be false (right part of the remaining area), than for it to be true.

Thus we have shown that in the central parameters approach and in the domains approach, additional information might be misleading in the sense that a correct answer is obtained without the information, but a wrong answer with the additional information. In contrast, this will never happen in the extreme parameters approach.

The question now is whether such a situation will happen frequently, and under which conditions such an undesirable reversal of results might occur. From Figure 3, it is clear that such a reversal is more likely to occur if the true parameter vector is located close to the boundary in parameter space separating the regions in which the statement is true and false, respectively, and at the same time it is close to the constraint generated by the additional information.

If the true parameter vector is close to the boundary line of the statement in question, this means that for the true parameters, the statement is not very robust. This underlines the importance of sensitivity analysis, which should be performed to check the robustness of any conclusions derived from our methods.

If an additional constraint is close to the true parameter vector, this indicates that the decision on which the constraint is based is a tight one and involves two alternatives which provide almost the same value for a negotiator. Since this additional constraint is also close to the boundary line of the statement in questions, we might for example have a situation in which alternative $x^{(i)}$ is being compared to an alternative which is similar to the reference value as well as to $x^{(i)}$ itself.

In real applications, a negotiator might be hesitant to make a preference statement about alternatives between which he is almost indifferent and thus we can expect that such reversals will not happen too often. On the other hand, such preference statements can not be completely avoided. If the mediator tries to use only preference statements about which the negotiators are very sure, this would generate only constraints far from the true parameter vector. Using only such constraints, it is not possible to reduce the set of feasible parameter vectors to a region close to the true vector. A large feasible region might be sufficient in some cases, but will often not be enough to obtain a unique solution. Our results indicate that such statements, even if they are correct (the true parameter vector remains feasible, thus the preference statement leading to the 
new line is in accordance with the true preferences) might generate misleading results.

The simulation studies we have performed to obtain the numerical results presented in section 4 provide further insights into the effects of additional information (for more details see [25]). On one hand, some results indicate that the information which can be inferred from choices made during the negotiation is not enough for reliable results, and the results can significantly be improved by adding at least a few preference or indifference statements directly obtained from the negotiators. On the other hand, just a few of those equivalence statements are sufficient to obtain results which are very close to the true preferences of negotiators. Therefore, it seems that one need not obtain much additional information from the negotiators.

\subsubsection{User-oriented comparison of the approaches}

Table 1 summarizes the different intervention possibilities for a mediator using the three approaches, which altogether can constitute a process with three steps.

The rows of Table 1 express the complementary concerns of a mediator. A mediator would like to propose an alternative likely to be accepted, hence better than the reference point for both negotiators. Three approaches can then be used:

- The extreme parameters approach will compute which alternatives are surely better than the reference point for both negotiators simultaneously (analysis 1a). However, it might turn out that no such alternatives exist. The same approach can be used to eliminate alternatives which are surely worse than the reference point for at least one negotiator (analysis 1b). The advantage of this approach is that the conditions of being surely better or surely worse are exactly determined. Its disadvantage is that it requires solving $n_{\text {alt }}$ LPs for each analysis (where $n_{\text {alt }}$ represents the number of possible alternatives, i.e. the number of different combinations of issue levels).

- The central parameters approach will find alternatives which are better than the reference point for both negotiators simultaneously, assuming a central parameter vector (analysis 1'). This vector can be computed solving a LP maximizing the minimum slack or computing a centroid. An advantage of this approach is that only two LPs need to be solved (one for each negotiator), or only two centroids have to be computed. Another advantage is that it provides a clear-cut partition of the alternatives set: those better than the reference, and those worse than the reference.

- The domains approach will compute the probabilities that each alternative is better than the reference point for both negotiators simultaneously (analysis 1"). Some alternatives will have zero or a very low probability and might be discarded from further analysis. The advantage of this approach is that it is straightforward to compute the probabilities using 
Table 1: Summary of the different analysis that can be performed

\begin{tabular}{|c|c|c|c|}
\hline Concept / Approach & Extreme & Central & Domains \\
\hline $\begin{array}{l}\text { Step 1: Com- } \\
\text { parison to } \\
\text { reference } \\
\text { point in } \\
\text { value space }\end{array}$ & $\begin{array}{l}\text { 1a. identify alter- } \\
\text { natives which } \\
\text { are surely } \\
\text { better than } \\
\text { the reference } \\
\text { point for both } \\
\text { negotiators } \\
\text { 1b. eliminate alter- } \\
\text { natives which } \\
\text { are surely } \\
\text { worse than } \\
\text { the reference } \\
\text { point for at } \\
\text { least one } \\
\text { negotiator }\end{array}$ & $\begin{array}{l}\text { 1'. identify alterna- } \\
\text { tives which } \\
\text { are better } \\
\text { than the } \\
\text { reference } \\
\text { point for both } \\
\text { negotiators, } \\
\text { assuming } \\
\text { the central } \\
\text { parameter } \\
\text { values (LP } \\
\text { solution or } \\
\text { centroid) }\end{array}$ & $\begin{array}{l}\text { 1". find the prob- } \\
\text { ability that } \\
\text { each alter- } \\
\text { native is } \\
\text { better than } \\
\text { the reference } \\
\text { point for both } \\
\text { negotiators }\end{array}$ \\
\hline Step $\underset{\text { Efficiency }}{\text { 2: Pareto }}$ & $\begin{array}{lr}\text { 2a. identify } & \text { al- } \\
\text { ternatives } \\
\text { which are } \\
\text { surely Pareto } \\
\text { efficient } \\
\text { 2b. eliminate } & \text { alter- } \\
\text { natives } & \text { which } \\
\text { are } & \text { surely } \\
\text { not Pareto } & \text { efficient }\end{array}$ & $\begin{array}{l}\text { 2'. identify alterna- } \\
\text { tives which } \\
\text { are Pareto } \\
\text { efficient, } \\
\text { assuming } \\
\text { the central } \\
\text { parameter } \\
\text { values (LP } \\
\text { solution or } \\
\text { centroid) }\end{array}$ & $\begin{array}{l}\text { 2". find the prob- } \\
\text { ability that } \\
\text { each alterna- } \\
\text { tive is Pareto } \\
\text { efficient }\end{array}$ \\
\hline $\begin{array}{c}\text { Step 3: Optimal } \\
\text { alterna- } \\
\text { tive using } \\
\text { mediation } \\
\text { criterion }\end{array}$ & $\begin{array}{lr}\text { 3a. identify alter- } \\
\text { natives which } \\
\text { are surely } \\
\text { optimal for } \\
\text { the mediation } \\
\text { criterion (for } \\
\text { all parameter } \\
\text { vectors) } \\
\text { 3b. identify alter- } \\
\text { natives which } \\
\text { might be } \\
\text { optimal for } \\
\text { the mediation } \\
\text { criterion (at } \\
\text { least for one } \\
\text { parameter } \\
\text { vector) }\end{array}$ & $\begin{array}{l}\text { 3'. identify alterna- } \\
\text { tives which } \\
\text { are optimal } \\
\text { for the media- } \\
\text { tion criterion, } \\
\text { assuming } \\
\text { the central } \\
\text { parameter } \\
\text { values (LP } \\
\text { solution or } \\
\text { centroid) }\end{array}$ & $\begin{array}{lr}\text { 3". find the prob- } \\
\text { ability that } \\
\text { each alter- } \\
\text { nativer is } \\
\text { optimal for } \\
\text { the mediation } \\
\text { criterion }\end{array}$ \\
\hline
\end{tabular}

Monte-Carlo simulation, with a confidence level as high as needed (it is a matter of how many iterations are used for the simulation). Its disadvantage is that the result will not be as clear cut as in the previous case. 
Concerning the second row of Table 1, a mediator would like to propose an alternative on the Pareto efficient frontier. Again, the same three approaches can be used:

- The extreme parameters approach will compute exactly which alternatives are surely efficient (analysis 2a), or surely not efficient (analysis 2b), allowing to eliminate the latter. Its disadvantage is that it requires solving $2 * n_{\text {alt }} *\left(n_{\text {alt }}-1\right)$ LPs for each analysis (this is a worst case bound, because as soon as an alternative is deemed surely inefficient, it is no longer necessary to include it in the subsequent comparisons). The advantage of this approach is that the conditions of being surely efficient or surely inefficient are exactly determined.

- The central parameters approach will find which alternatives are efficient, assuming a central parameter vector computed solving an LP or computing a centroid (analysis 2'). An advantage of this approach is that only two LPs or centroid computations are needed. It also provides a clear-cut partition of the alternatives set between efficient and inefficient ones.

- The domains approach will compute the probabilities that each alternative is efficient (analysis 2"). Alternatives with a very low probability of being efficient might be discarded from further analysis. The advantage and the disadvantage are the same as for analysis 1".

Finally, concerning the third row of Table 1, a mediator could have the requirement of proposing an efficient alternative that would be optimal according to a mediation criterion such as the sum of the values (pursuing maximal enlargement of the pie) or the minimum PoP (pursuing equity):

- The extreme parameters approach will indicate if an optimal alternative for all parameter values exists (analysis 3a), which is not very likely, and will determine which alternatives might be optimal (analysis 3b). As an advantage, the conditions of being surely optimal or potentially optimal are exactly determined. However, the most likely result will be a set of potentially optimal alternatives, with no way of knowing which one is better. Furthermore, the use of linear programming is limited to the case where the mediation criterion is the sum of values.

- The central parameters approach will find the optimal alternative, assuming a central parameter vector (analysis $3 '$ '). An advantage of this approach is that a single alternative will be identified (except for rare cases where multiple alternative optima might exist). A second advantage is that the mediation criterion does not have to be linear, the minimum PoP as a mediation criterion, or a criterion involving products, can also be computed easily for a given parameter vector.

- The domains approach will compute the probabilities of each alternative being optimal (analysis 3"). Alternatives with a very low probability of 
being optimal might be discarded from further analysis. The advantage of this approach is that by using Monte-Carlo simulation, probabilities for several mediation clriteria can be computed simultaneously and also non-linear criteria can be used. A clear cut result is not very likely, but this analysis provides more information than analysis $3 \mathrm{~b}$, because it also includes probabilities.

All the presented approaches provide interesting and diversified results. The choice of the approaches to be used depends on the mediator's goals, but we suggest to use different approaches complementarily in sequence.

The mediator can start by finding alternatives that both negotiators would consider to be an improvement relatively to the reference point. This implies eliminating alternatives which are surely worse than the reference for at least one negotiator (analysis 1b), or which have only a very low probability of being better than the reference for both negotiators (analysis 1"). In a second step, the mediator can eliminate alternatives that are surely inefficient (analysis 2b) or very unlikely to be efficient (analysis 2"), the latter approach being preferable if there remain many alternatives. To detect efficiency, each of the alternatives that was not eliminated in the previous step would be compared with the original set of alternatives. Finally, to choose a single alternative to propose to both negotiators, the mediator can use analysis 3' to propose the optimal solution using central parameters, or use analysis 3" to pick the alternative that is optimal with highest probability. For this purpose, more than one mediation criterion can be considered.

As referred previously, this integrated approach can be used interactively. If the alternative proposed by the mediator is accepted, the negotiation ends successfully. However, a situation can arise in which the alternative proposed by the mediator is not accepted by one negotiator (or both). If a negotiator $k$ states that a proposed solution $x^{(p)}$ is not better than the reference $x^{(r)}$, the constraint $V^{k}\left(x^{(p)}\right)<V^{k}\left(x^{(r)}\right)$ can be added to the definition of $\left(W_{k}, M_{k}\right)$. The analysis can then be repeated to find a new solution. A negotiator might be insincere (act strategically) when stating that $x^{(p)}$ is not better than the reference, hoping that a better alternative will proposed by the mediator. However, since the mediator will incorporate the constraint $V^{k}\left(x^{(p)}\right)<V^{k}\left(x^{(r)}\right)$, which is contrary to the negotiator's true preferences, the negotiator's true parameter vector will be excluded from the feasible region. It therefore might happen that the following alternatives proposed will not be as good as the previous one. For this reason, it is likely that manipulation attempts will eventually harm the negotiator who tried to manipulate the process.

Although the columns of Table 1 show three different approaches, they can all be performed in one single Monte-Carlo simulation. Indeed, Monte-Carlo simulation can be used to compute probabilities (relative domains) for different conditions with high accuracy, depending on the number of parameter vectors in the sample. Averaging the feasible parameter across all iterations will provide an accurate approximation of the centroid of $\left(W_{1}, M_{1}\right)$ and $\left(W_{2}, M_{2}\right)$, which can be used in the central parameters approach. Simulation experiments with 
a large number of parameter vectors will also provide a good approximation of the extreme parameters approach, however, exact results can only be obtained by solving the corresponding LP problems.

\section{Illustrative Example}

\subsection{Introduction}

To illustrate the approaches presented in the last section, let us consider an example introduced by Raiffa [23]. In this example, there are two parties in a negotiation: Nelson and Amstore. Nelson has a construction firm and he negotiates with a retail chain (Amstore) to build a new store for them. There are three issues: price $(10,10.5,11,11.5$ or 12 thousand dollars), design (basic or improved) and time $(20,21,22,23,24,25$ or 26 days). Combining these issue levels yields a total of 70 possible alternatives (see Table 2). Nelson wants to maximize the issues price and time and prefers basic over improved design, while Amstore has the opposite preferences. Therefore, the most preferred alternative for Amstore is alternative 1, whereas the most preferred alternative for Nelson is alternative 70 . The sequence of proposals and the compromise eventually reached (alternative 44) are depicted in Figure 4.

Figure 4: Dance of the Packages.

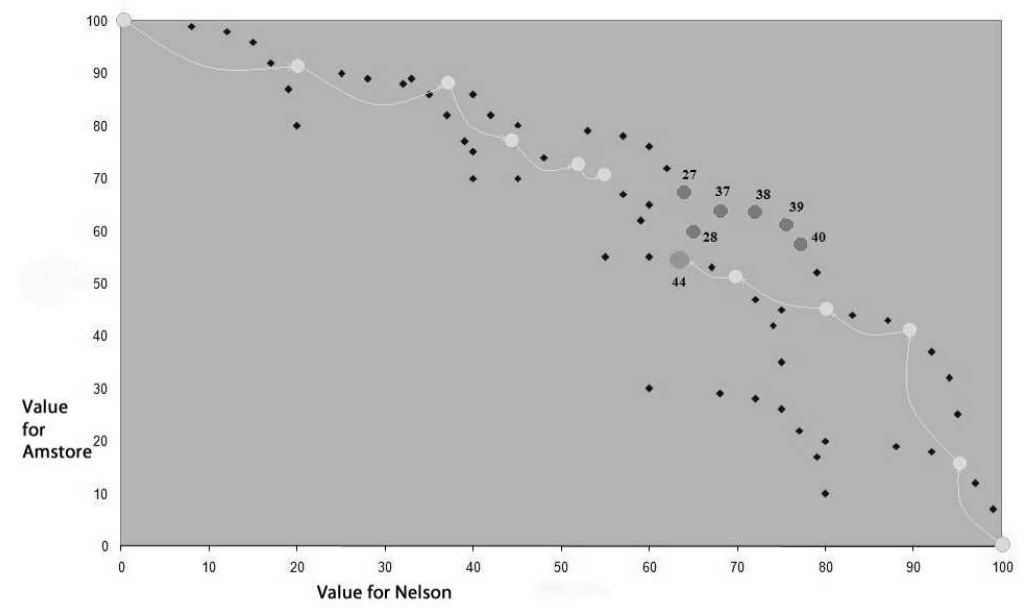

In this illustration, we consider only the mediation criterion of maximizing the sum of the values. Among the efficient alternatives that are better than the compromise for both parties, alternative 39 is the best one, with a sum of values equal to 136 . Alternative 25 also has the same total value, but it is not better for both parties than the compromise solution. Therefore, a mediator having 
Table 2: Alternatives

\begin{tabular}{cccc|cccc|cccc}
\hline Alt. & Price & Design & Time & Alt. & Price & Design & Time & Alt. & Price & Design & Time \\
\hline 1 & 10 & Imp. & 20 & 25 & 10.5 & Basic & 23 & 49 & 11.5 & Imp. & 26 \\
2 & 10 & Imp. & 21 & 26 & 10.5 & Basic & 24 & 50 & 11.5 & Basic & 20 \\
3 & 10 & Imp. & 22 & 27 & 10.5 & Basic & 25 & 51 & 11.5 & Basic & 21 \\
4 & 10 & Imp. & 23 & 28 & 10.5 & Basic & 26 & 52 & 11.5 & Basic & 22 \\
5 & 10 & Imp. & 24 & 29 & 11 & Imp. & 20 & 53 & 11.5 & Basic & 23 \\
6 & 10 & Imp. & 25 & 30 & 11 & Imp. & 21 & 54 & 11.5 & Basic & 24 \\
7 & 10 & Imp. & 26 & 31 & 11 & Imp. & 22 & 55 & 11.5 & Basic & 25 \\
8 & 10 & Basic & 20 & 32 & 11 & Imp. & 23 & 56 & 11.5 & Basic & 26 \\
9 & 10 & Basic & 21 & 33 & 11 & Imp. & 24 & 57 & 12 & Imp. & 20 \\
10 & 10 & Basic & 22 & 34 & 11 & Imp. & 25 & 58 & 12 & Imp. & 21 \\
11 & 10 & Basic & 23 & 35 & 11 & Imp. & 26 & 59 & 12 & Imp. & 22 \\
12 & 10 & Basic & 24 & 36 & 11 & Basic & 20 & 60 & 12 & Imp. & 23 \\
13 & 10 & Basic & 25 & 37 & 11 & Basic & 21 & 61 & 12 & Imp. & 24 \\
14 & 10 & Basic & 26 & 38 & 11 & Basic & 22 & 62 & 12 & Imp. & 25 \\
15 & 10.5 & Imp. & 20 & 39 & 11 & Basic & 23 & 63 & 12 & Imp. & 26 \\
16 & 10.5 & Imp. & 21 & 40 & 11 & Basic & 24 & 64 & 12 & Basic & 20 \\
17 & 10.5 & Imp. & 22 & 41 & 11 & Basic & 25 & 65 & 12 & Basic & 21 \\
18 & 10.5 & Imp. & 23 & 42 & 11 & Basic & 26 & 66 & 12 & Basic & 22 \\
19 & 10.5 & Imp. & 24 & 43 & 11.5 & Imp. & 20 & 67 & 12 & Basic & 23 \\
20 & 10.5 & Imp. & 25 & 44 & 11.5 & Imp. & 21 & 68 & 12 & Basic & 24 \\
21 & 10.5 & Imp. & 26 & 45 & 11.5 & Imp. & 22 & 69 & 12 & Basic & 25 \\
22 & 10.5 & Basic & 20 & 46 & 11.5 & Imp. & 23 & 70 & 12 & Basic & 26 \\
23 & 10.5 & Basic & 21 & 47 & 11.5 & Imp. & 24 & & & & \\
24 & 10.5 & Basic & 22 & 48 & 11.5 & Imp. & 25 & & & & \\
\hline
\end{tabular}


Table 3: Complete Information.

\begin{tabular}{crrrrr}
\hline & & \multicolumn{2}{c}{ Partial value } & \multicolumn{2}{c}{ Value*100 } \\
Issue & Level & Nelson & Amstore & Nelson & Amstore \\
\hline \multirow{5}{*}{ Price } & 10 & 0 & 1 & 0 & 70 \\
& 10.5 & 0.41667 & 0.85714 & 25 & 60 \\
& 11 & 0.66667 & 0.64286 & 40 & 45 \\
& 11.5 & 0.91667 & 0.35714 & 55 & 25 \\
& 12 & 1 & 0 & 60 & 0 \\
\hline \multirow{5}{*}{ Timesign } & $w_{1}$ & 0.6 & 0.7 & & \\
& Basic & 1 & 0 & 20 & 0 \\
& Improved & 0 & 1 & 0 & 10 \\
& $w_{2}$ & 0.2 & 0.1 & & \\
\hline & 20 & 0 & 1 & 0 & 20 \\
& 21 & 0.4 & 0.95 & 8 & 19 \\
& 22 & 0.6 & 0.9 & 12 & 18 \\
& 23 & 0.75 & 0.8 & 15 & 16 \\
& 24 & 0.85 & 0.6 & 17 & 12 \\
& 25 & 0.95 & 0.35 & 19 & 7 \\
& 26 & 1 & 0 & 20 & 0 \\
& $w_{3}$ & 0.2 & 0.2 & & \\
\hline
\end{tabular}

complete information would propose alternative 39 to the parties.

Let us now consider the analysis of a mediator who knows the available alternatives (Table 2) and witnesses the sequence of proposals, but does not know the exact parameter values of each negotiator displayed in Table 3 . The sequence of proposals originates constraints of type (6). To illustrate the use of explicit preference information (namely, constraints of type (7)), suppose that Nelson indicates that alternative 25 is as good as alternative 36 , and alternative 39 is as good as alternative 50. Let us also assume that Amstore provides the information that alternatives 50 and 42 as well as alternatives 36 and 37 are roughly equivalent. We decided to use $c=5$ in (5) so that the real values belong to the interval with the linear function as lower limit and the concave function as upper limit, but without considering that value functions could be extremely concave. For the constraints of type (7) we used $\epsilon=10$.

\subsection{Comparison of the recommendations provided by the different approaches}

In this example, we consider only the recommendations that would be given by the mediator in the first step, without interactive refinement. The results obtained assuming known value functions are presented in Table 4 and results assuming unknown value functions in Table 5. For our calculations, we used constraints of type $(6)+(7)$. Considering the central approach we present the results obtained solving the LPs. The results for the domains approach were 
obtained using 5000 iterations in a Monte Carlo simulation.

These tables:

- show the probabilities obtained in the domains approach (probability of being better for both parties than the compromise solution, probability of being efficient and probability of being the best according the criterion of maximizing the sum of the values);

- indicate if one alternative is possibly / surely better than the compromise solution for both negotiators, possibly / surely efficient and possibly / surely the best one according the criterion of maximizing the sum of the values;

- present the results considering the central parameters approach (indicating if this approach indicates or not an alternative as being better than the compromise for both negotiators, of being efficient and of maximizing the sum of the values).

In these tables, one can observe the difference between a simulation approach and the exact solution of LP models in the extreme parameters approach. Theoretically, an alternative should be surely better than the compromise exactly if the probability of being better than the compromise is one. But since probabilities are obtained via simulation with a finite number of parameter vectors, it is possible that for some alternatives, the probability is estimated to be one, while the exact solution of the LP model still indicates that it is not better for some parameter vectors and thus it is not surely better. This was the case for alternatives 38 and 40 in Table 4 . The tables also show the possibility that the central parameters approach generates misleading results. For example, alternative 41 is indicated as being better than the compromise, although the domain approach reveals that the probability of this property is only about $65 \%$.

Considering known values (but unknown weights), in all the approaches, the mediator should recommend alternative 39. Alternative 39 is in reality better for both parties than the compromise solution and it is efficient. Considering value functions with unknown parameters, and using the extreme parameters approach, it is only possible to recommend a set of 15 alternatives that can be better for both parties than the compromise solution, can be efficient and can maximize the sum of the values. Considering the central approach it is possible to recommend alternative 38 (after using the approach interactively), in the criterion maximizing the sum of the values. This alternative is in reality better for both parties than the compromise solution and efficient. Considering the domains approach, if the objective is to maximize the sum of the values the mediator should suggest alternatives 26 and 27 (both alternatives are efficient, but alternative 26 is not better for Nelson than the compromise solution). Table 6 summarizes the results of the three approaches to facilitate their comparison.

Figure 5 shows the positions of these solutions in value space. The comparison to the reference point helps to eliminate a large fraction of the alternatives, even in the case of unknown value functions. The difference between the two 
Table 4: Results of the three approaches considering known values.

\begin{tabular}{|c|c|c|c|c|c|c|c|c|c|}
\hline & Better tl & an the co & ppromise & & Efficient & & & Sum & \\
\hline Alt & Domain & $\begin{array}{l}\text { Poss. } \\
\text { /Surely }\end{array}$ & $\begin{array}{c}\text { Cent. } \\
\text { Param. }\end{array}$ & Domain & $\begin{array}{l}\text { Poss. } \\
\text { /Surely }\end{array}$ & $\begin{array}{c}\text { Cent. } \\
\text { Param. }\end{array}$ & Domain & $\begin{array}{l}\text { Poss. } \\
\text { /Surely }\end{array}$ & $\begin{array}{c}\text { Cent. } \\
\text { Param. }\end{array}$ \\
\hline 1 & 0 & $\mathrm{n} / \mathrm{n}$ & $\mathrm{n}$ & 1 & $\mathrm{y} / \mathrm{n}$ & $\mathrm{n}$ & 0 & $\mathrm{n} / \mathrm{n}$ & $\mathrm{n}$ \\
\hline 2 & 0 & $\mathrm{n} / \mathrm{n}$ & $\mathrm{n}$ & 1 & $\mathrm{y} / \mathrm{n}$ & $\mathrm{n}$ & 0 & $\mathrm{n} / \mathrm{n}$ & $\mathrm{n}$ \\
\hline 3 & 0 & $\mathrm{n} / \mathrm{n}$ & $\mathrm{n}$ & 0.9638 & $\mathrm{y} / \mathrm{n}$ & $\mathrm{n}$ & 0 & $\mathrm{n} / \mathrm{n}$ & $\mathrm{n}$ \\
\hline 4 & 0 & $\mathrm{n} / \mathrm{n}$ & $\mathrm{n}$ & 0.6340 & $\mathrm{y} / \mathrm{n}$ & $\mathrm{n}$ & 0 & $\mathrm{n} / \mathrm{n}$ & $\mathrm{n}$ \\
\hline 5 & 0 & $\mathrm{n} / \mathrm{n}$ & $\mathrm{n}$ & 0.2050 & $\mathrm{y} / \mathrm{n}$ & $\mathrm{n}$ & 0 & $\mathrm{n} / \mathrm{n}$ & $\mathrm{n}$ \\
\hline 6 & 0 & $\mathrm{n} / \mathrm{n}$ & $\mathrm{n}$ & 0 & $\mathrm{y} / \mathrm{n}$ & $\mathrm{n}$ & 0 & $\mathrm{n} / \mathrm{n}$ & $\mathrm{n}$ \\
\hline 7 & 0 & $\mathrm{n} / \mathrm{n}$ & $\mathrm{n}$ & 0 & $\mathrm{y} / \mathrm{n}$ & $\mathrm{n}$ & 0 & $\mathrm{n} / \mathrm{n}$ & $\mathrm{n}$ \\
\hline 8 & 0 & $\mathrm{n} / \mathrm{n}$ & $\mathrm{n}$ & 0.6400 & $\mathrm{y} / \mathrm{n}$ & $\mathrm{n}$ & 0 & $\mathrm{n} / \mathrm{n}$ & $\mathrm{n}$ \\
\hline 9 & 0 & $\mathrm{n} / \mathrm{n}$ & $\mathrm{n}$ & 0.9644 & $\mathrm{y} / \mathrm{n}$ & $\mathrm{n}$ & 0 & $\mathrm{n} / \mathrm{n}$ & $\mathrm{n}$ \\
\hline 10 & 0 & $\mathrm{n} / \mathrm{n}$ & $\mathrm{n}$ & 0.9406 & $\mathrm{y} / \mathrm{n}$ & $\mathrm{n}$ & 0 & $\mathrm{n} / \mathrm{n}$ & $\mathrm{n}$ \\
\hline 11 & 0 & $\mathrm{n} / \mathrm{n}$ & $\mathrm{n}$ & 0.8542 & $\mathrm{y} / \mathrm{n}$ & $\mathrm{n}$ & 0 & $\mathrm{n} / \mathrm{n}$ & $\mathrm{n}$ \\
\hline 12 & 0 & $\mathrm{y} / \mathrm{n}$ & $\mathrm{n}$ & 0.6474 & $\mathrm{y} / \mathrm{n}$ & $\mathrm{n}$ & 0 & $\mathrm{y} / \mathrm{n}$ & $\mathrm{n}$ \\
\hline 13 & 0.0102 & $\mathrm{y} / \mathrm{n}$ & $\mathrm{n}$ & 0 & $\mathrm{n} / \mathrm{n}$ & $\mathrm{n}$ & 0 & $\mathrm{n} / \mathrm{n}$ & $\mathrm{n}$ \\
\hline 14 & 0.0380 & $\mathrm{y} / \mathrm{n}$ & $\mathrm{n}$ & 0 & $\mathrm{n} / \mathrm{n}$ & $\mathrm{n}$ & 0 & $\mathrm{n} / \mathrm{n}$ & $\mathrm{n}$ \\
\hline 15 & 0 & $\mathrm{n} / \mathrm{n}$ & $\mathrm{n}$ & 0.0790 & $\mathrm{y} / \mathrm{n}$ & $\mathrm{n}$ & 0 & $\mathrm{n} / \mathrm{n}$ & $\mathrm{n}$ \\
\hline 16 & 0 & $\mathrm{n} / \mathrm{n}$ & $\mathrm{n}$ & 0.2718 & $\mathrm{y} / \mathrm{n}$ & $\mathrm{n}$ & 0 & $\mathrm{n} / \mathrm{n}$ & $\mathrm{n}$ \\
\hline 17 & 0 & $\mathrm{n} / \mathrm{n}$ & $\mathrm{n}$ & 0.4750 & $\mathrm{y} / \mathrm{n}$ & $\mathrm{n}$ & 0 & $\mathrm{n} / \mathrm{n}$ & $\mathrm{n}$ \\
\hline 18 & 0 & $\mathrm{n} / \mathrm{n}$ & $\mathrm{n}$ & 0.4110 & $\mathrm{y} / \mathrm{n}$ & $\mathrm{n}$ & 0 & $\mathrm{n} / \mathrm{n}$ & $\mathrm{n}$ \\
\hline 19 & 0 & $\mathrm{n} / \mathrm{n}$ & $\mathrm{n}$ & 0.1652 & $\mathrm{y} / \mathrm{n}$ & $\mathrm{n}$ & 0 & $\mathrm{n} / \mathrm{n}$ & $\mathrm{n}$ \\
\hline 20 & 0 & $\mathrm{n} / \mathrm{n}$ & $\mathrm{n}$ & 0 & $\mathrm{y} / \mathrm{n}$ & $\mathrm{n}$ & 0 & $\mathrm{n} / \mathrm{n}$ & $\mathrm{n}$ \\
\hline 21 & 0 & $\mathrm{n} / \mathrm{n}$ & $\mathrm{n}$ & 0 & $\mathrm{y} / \mathrm{n}$ & $\mathrm{n}$ & 0 & $\mathrm{n} / \mathrm{n}$ & $\mathrm{n}$ \\
\hline 22 & 0 & $\mathrm{y} / \mathrm{n}$ & $\mathrm{n}$ & 0.4420 & $\mathrm{y} / \mathrm{n}$ & $\mathrm{n}$ & 0 & $\mathrm{y} / \mathrm{n}$ & $\mathrm{n}$ \\
\hline 23 & 0.1310 & $\mathrm{y} / \mathrm{n}$ & $\mathrm{n}$ & 0.9972 & $\mathrm{y} / \mathrm{n}$ & $\mathrm{n}$ & 0 & $\mathrm{y} / \mathrm{n}$ & $\mathrm{n}$ \\
\hline 24 & 0.3514 & $\mathrm{y} / \mathrm{n}$ & $\mathrm{n}$ & 1 & $\mathrm{y} / \mathrm{n}$ & $\mathrm{n}$ & 0 & $\mathrm{y} / \mathrm{n}$ & $\mathrm{n}$ \\
\hline 25 & 0.5856 & $\mathrm{y} / \mathrm{n}$ & $\mathrm{n}$ & 1 & $\mathrm{y} / \mathrm{n}$ & $\mathrm{n}$ & 0.5856 & $\mathrm{y} / \mathrm{n}$ & $\mathrm{n}$ \\
\hline 26 & 0.7038 & $\mathrm{y} / \mathrm{n}$ & $\mathrm{n}$ & 1 & $\mathrm{y} / \mathrm{n}$ & $\mathrm{n}$ & 0.0330 & $\mathrm{y} / \mathrm{n}$ & $\mathrm{n}$ \\
\hline 27 & 0.8268 & $\mathrm{y} / \mathrm{n}$ & $\mathrm{n}$ & 0.9724 & $\mathrm{y} / \mathrm{n}$ & $\mathrm{n}$ & 0 & $\mathrm{y} / \mathrm{n}$ & $\mathrm{n}$ \\
\hline 28 & 0.8552 & $\mathrm{y} / \mathrm{n}$ & $\mathrm{n}$ & 0 & $\mathrm{y} / \mathrm{n}$ & $\mathrm{n}$ & 0 & $\mathrm{y} / \mathrm{n}$ & $\mathrm{n}$ \\
\hline 29 & 0 & $\mathrm{n} / \mathrm{n}$ & $\mathrm{n}$ & 0 & $\mathrm{y} / \mathrm{n}$ & $\mathrm{n}$ & 0 & $\mathrm{n} / \mathrm{n}$ & $\mathrm{n}$ \\
\hline 30 & 0 & $\mathrm{n} / \mathrm{n}$ & $\mathrm{n}$ & 0 & $\mathrm{y} / \mathrm{n}$ & $\mathrm{n}$ & 0 & $\mathrm{n} / \mathrm{n}$ & $\mathrm{n}$ \\
\hline 31 & 0 & $\mathrm{n} / \mathrm{n}$ & $\mathrm{n}$ & 0 & $\mathrm{y} / \mathrm{n}$ & $\mathrm{n}$ & 0 & $\mathrm{n} / \mathrm{n}$ & $\mathrm{n}$ \\
\hline 32 & 0 & $\mathrm{n} / \mathrm{n}$ & $\mathrm{n}$ & 0.0032 & $\mathrm{y} / \mathrm{n}$ & $\mathrm{n}$ & 0 & $\mathrm{n} / \mathrm{n}$ & $\mathrm{n}$ \\
\hline 33 & 0.2208 & $\mathrm{y} / \mathrm{n}$ & $\mathrm{n}$ & 0.0100 & $\mathrm{y} / \mathrm{n}$ & $\mathrm{n}$ & 0 & $\mathrm{y} / \mathrm{n}$ & $\mathrm{n}$ \\
\hline 34 & 0.4534 & $\mathrm{y} / \mathrm{n}$ & $\mathrm{n}$ & 0 & $\mathrm{n} / \mathrm{n}$ & $\mathrm{n}$ & 0 & $\mathrm{n} / \mathrm{n}$ & $\mathrm{n}$ \\
\hline 35 & 0.2254 & $\mathrm{y} / \mathrm{n}$ & $\mathrm{n}$ & 0 & $\mathrm{n} / \mathrm{n}$ & $\mathrm{n}$ & 0 & $\mathrm{n} / \mathrm{n}$ & $\mathrm{n}$ \\
\hline 36 & 0.2422 & $\mathrm{y} / \mathrm{n}$ & $\mathrm{n}$ & 0 & $\mathrm{n} / \mathrm{n}$ & $\mathrm{n}$ & 0 & $\mathrm{n} / \mathrm{n}$ & $\mathrm{n}$ \\
\hline 37 & 0.8506 & $\mathrm{y} / \mathrm{n}$ & $\mathrm{n}$ & 0.5592 & $\mathrm{y} / \mathrm{n}$ & $\mathrm{n}$ & 0 & $\mathrm{y} / \mathrm{n}$ & $\mathrm{n}$ \\
\hline 38 & 1 & $\mathrm{y} / \mathrm{n}$ & $\mathrm{y}$ & 1 & $\mathrm{y} / \mathrm{n}$ & $\mathrm{y}$ & 0 & $\mathrm{y} / \mathrm{n}$ & $\mathrm{n}$ \\
\hline 39 & 1 & $\mathrm{y} / \mathrm{y}$ & $\mathrm{y}$ & 1 & $\mathrm{y} / \mathrm{n}$ & $\mathrm{y}$ & 0.3814 & $\mathrm{y} / \mathrm{n}$ & $\mathrm{y}$ \\
\hline 40 & 1 & $\mathrm{y} / \mathrm{n}$ & $\mathrm{y}$ & 1 & $\mathrm{y} / \mathrm{n}$ & $\mathrm{y}$ & 0 & $\mathrm{y} / \mathrm{n}$ & $\mathrm{n}$ \\
\hline 41 & 0.6490 & $\mathrm{y} / \mathrm{n}$ & $\mathrm{y}$ & 1 & $\mathrm{y} / \mathrm{n}$ & $\mathrm{y}$ & 0 & $\mathrm{y} / \mathrm{n}$ & $\mathrm{n}$ \\
\hline 42 & 0.0140 & $\mathrm{y} / \mathrm{n}$ & $\mathrm{n}$ & 0.4706 & $\mathrm{y} / \mathrm{n}$ & $\mathrm{n}$ & 0 & $\mathrm{y} / \mathrm{n}$ & $\mathrm{n}$ \\
\hline 43 & 0 & $\mathrm{n} / \mathrm{n}$ & 27 & 0 & $\mathrm{y} / \mathrm{n}$ & $\mathrm{n}$ & 0 & $\mathrm{n} / \mathrm{n}$ & $\mathrm{n}$ \\
\hline 44 & 0 & $\mathrm{n} / \mathrm{n}$ & $\mathrm{n}$ & 0 & $\mathrm{y} / \mathrm{n}$ & $\mathrm{n}$ & 0 & $\mathrm{n} / \mathrm{n}$ & $\mathrm{n}$ \\
\hline 45 & 0 & $\mathrm{n} / \mathrm{n}$ & $\mathrm{n}$ & 0 & $\mathrm{y} / \mathrm{n}$ & $\mathrm{n}$ & 0 & $\mathrm{n} / \mathrm{n}$ & $\mathrm{n}$ \\
\hline 46 & 0 & $\mathrm{n} / \mathrm{n}$ & $\mathrm{n}$ & 0 & $\mathrm{y} / \mathrm{n}$ & $\mathrm{n}$ & 0 & $\mathrm{n} / \mathrm{n}$ & $\mathrm{n}$ \\
\hline 47 & 0 & $\mathrm{n} / \mathrm{n}$ & $\mathrm{n}$ & 0.0006 & $\mathrm{y} / \mathrm{n}$ & $\mathrm{n}$ & 0 & $\mathrm{n} / \mathrm{n}$ & $\mathrm{n}$ \\
\hline 48 & 0 & $\mathrm{n} / \mathrm{n}$ & $\mathrm{n}$ & 0 & $\mathrm{y} / \mathrm{n}$ & $\mathrm{n}$ & 0 & $\mathrm{n} / \mathrm{n}$ & $\mathrm{n}$ \\
\hline 49 & 0 & $\mathrm{n} / \mathrm{n}$ & $\mathrm{n}$ & 0 & $\mathrm{y} / \mathrm{n}$ & $\mathrm{n}$ & 0 & $\mathrm{n} / \mathrm{n}$ & $\mathrm{n}$ \\
\hline 50 & 0 & $\mathrm{y} / \mathrm{n}$ & $\mathrm{n}$ & 0 & $\mathrm{n} / \mathrm{n}$ & $\mathrm{n}$ & 0 & $\mathrm{n} / \mathrm{n}$ & $\mathrm{n}$ \\
\hline
\end{tabular}


Table 5: Results of the three approaches considering unknown values.

\begin{tabular}{|c|c|c|c|c|c|c|c|c|c|}
\hline \multirow[b]{2}{*}{ Alt } & \multicolumn{3}{|c|}{ Better than the compromisse } & \multicolumn{3}{|c|}{ Efficient } & \multicolumn{3}{|c|}{ Sum } \\
\hline & Domain & $\begin{array}{l}\text { Poss. } \\
\text { /Surely }\end{array}$ & $\begin{array}{l}\text { Cent. } \\
\text { Param. }\end{array}$ & Domain & $\begin{array}{l}\text { Poss. } \\
\text { /Surely }\end{array}$ & $\begin{array}{l}\text { Cent. } \\
\text { Param. }\end{array}$ & Domain & $\begin{array}{l}\text { Poss. } \\
\text { /Surely }\end{array}$ & $\begin{array}{l}\text { Cent. } \\
\text { Param. }\end{array}$ \\
\hline 1 & 0 & $\mathrm{n} / \mathrm{n}$ & $\mathrm{n}$ & 1 & $\mathrm{y} / \mathrm{n}$ & $\mathrm{n}$ & 0 & $\mathrm{n} / \mathrm{n}$ & $\mathrm{n}$ \\
\hline 2 & 0 & $\mathrm{n} / \mathrm{n}$ & $\mathrm{n}$ & 0.8930 & $\mathrm{y} / \mathrm{n}$ & $\mathrm{n}$ & 0 & $\mathrm{n} / \mathrm{n}$ & $\mathrm{n}$ \\
\hline 3 & 0 & $\mathrm{n} / \mathrm{n}$ & $\mathrm{n}$ & 0.5664 & $\mathrm{y} / \mathrm{n}$ & $\mathrm{n}$ & 0 & $\mathrm{n} / \mathrm{n}$ & $\mathrm{n}$ \\
\hline 4 & 0 & $\mathrm{n} / \mathrm{n}$ & $\mathrm{n}$ & 0.3424 & $\mathrm{y} / \mathrm{n}$ & $\mathrm{n}$ & 0 & $\mathrm{n} / \mathrm{n}$ & $\mathrm{n}$ \\
\hline 5 & 0 & $\mathrm{n} / \mathrm{n}$ & $\mathrm{n}$ & 0.2074 & $\mathrm{y} / \mathrm{n}$ & $\mathrm{n}$ & 0 & $\mathrm{n} / \mathrm{n}$ & $\mathrm{n}$ \\
\hline 6 & 0 & $\mathrm{n} / \mathrm{n}$ & $\mathrm{n}$ & 0.1212 & $\mathrm{y} / \mathrm{n}$ & $\mathrm{n}$ & 0 & $\mathrm{n} / \mathrm{n}$ & $\mathrm{n}$ \\
\hline 7 & 0 & $\mathrm{n} / \mathrm{n}$ & $\mathrm{n}$ & 0.0292 & $\mathrm{y} / \mathrm{n}$ & $\mathrm{n}$ & 0 & $\mathrm{n} / \mathrm{n}$ & $\mathrm{n}$ \\
\hline 8 & 0 & $\mathrm{n} / \mathrm{n}$ & $\mathrm{n}$ & 0.6334 & $\mathrm{y} / \mathrm{n}$ & $\mathrm{n}$ & 0 & $\mathrm{n} / \mathrm{n}$ & $\mathrm{n}$ \\
\hline 9 & 0 & $\mathrm{y} / \mathrm{n}$ & $\mathrm{n}$ & 0.6670 & $\mathrm{y} / \mathrm{n}$ & $\mathrm{n}$ & 0 & $\mathrm{y} / \mathrm{n}$ & $\mathrm{n}$ \\
\hline 10 & 0.0032 & $\mathrm{y} / \mathrm{n}$ & $\mathrm{n}$ & 0.5536 & $\mathrm{y} / \mathrm{n}$ & $\mathrm{n}$ & 0 & $\mathrm{y} / \mathrm{n}$ & $\mathrm{n}$ \\
\hline 11 & 0.0106 & $\mathrm{y} / \mathrm{n}$ & $\mathrm{n}$ & 0.4398 & $\mathrm{y} / \mathrm{n}$ & $\mathrm{n}$ & 0 & $\mathrm{y} / \mathrm{n}$ & $\mathrm{n}$ \\
\hline 12 & 0.0326 & $\mathrm{y} / \mathrm{n}$ & $\mathrm{n}$ & 0.3372 & $\mathrm{y} / \mathrm{n}$ & $\mathrm{n}$ & 0 & $\mathrm{y} / \mathrm{n}$ & $\mathrm{n}$ \\
\hline 13 & 0.0702 & $\mathrm{y} / \mathrm{n}$ & $\mathrm{n}$ & 0.2484 & $\mathrm{y} / \mathrm{n}$ & $\mathrm{n}$ & 0.0077 & $\mathrm{y} / \mathrm{n}$ & $\mathrm{n}$ \\
\hline 14 & 0.1108 & $\mathrm{y} / \mathrm{n}$ & $\mathrm{n}$ & 0.0928 & $\mathrm{y} / \mathrm{n}$ & $\mathrm{n}$ & 0.0028 & $\mathrm{y} / \mathrm{n}$ & $\mathrm{n}$ \\
\hline 15 & 0 & $\mathrm{n} / \mathrm{n}$ & $\mathrm{n}$ & 0.5118 & $\mathrm{y} / \mathrm{n}$ & $\mathrm{n}$ & 0 & $\mathrm{n} / \mathrm{n}$ & $\mathrm{n}$ \\
\hline 16 & 0 & $\mathrm{n} / \mathrm{n}$ & $\mathrm{n}$ & 0.5532 & $\mathrm{y} / \mathrm{n}$ & $\mathrm{n}$ & 0 & $\mathrm{n} / \mathrm{n}$ & $\mathrm{n}$ \\
\hline 17 & 0 & $\mathrm{n} / \mathrm{n}$ & $\mathrm{n}$ & 0.3960 & $\mathrm{y} / \mathrm{n}$ & $\mathrm{n}$ & 0 & $\mathrm{n} / \mathrm{n}$ & $\mathrm{n}$ \\
\hline 18 & 0 & $\mathrm{n} / \mathrm{n}$ & $\mathrm{n}$ & 0.2736 & $\mathrm{y} / \mathrm{n}$ & $\mathrm{n}$ & 0 & $\mathrm{n} / \mathrm{n}$ & $\mathrm{n}$ \\
\hline 19 & 0 & $\mathrm{n} / \mathrm{n}$ & $\mathrm{n}$ & 0.1908 & $\mathrm{y} / \mathrm{n}$ & $\mathrm{n}$ & 0 & $\mathrm{n} / \mathrm{n}$ & $\mathrm{n}$ \\
\hline 20 & 0 & $\mathrm{n} / \mathrm{n}$ & $\mathrm{n}$ & 0.1346 & $\mathrm{y} / \mathrm{n}$ & $\mathrm{n}$ & 0 & $\mathrm{n} / \mathrm{n}$ & $\mathrm{n}$ \\
\hline 21 & 0.0448 & $\mathrm{y} / \mathrm{n}$ & $\mathrm{n}$ & 0.0330 & $\mathrm{y} / \mathrm{n}$ & $\mathrm{n}$ & 0 & $\mathrm{y} / \mathrm{n}$ & $\mathrm{n}$ \\
\hline 22 & 0.0152 & $\mathrm{y} / \mathrm{n}$ & $\mathrm{n}$ & 0.6234 & $\mathrm{y} / \mathrm{n}$ & $\mathrm{n}$ & 0 & $\mathrm{y} / \mathrm{n}$ & $\mathrm{n}$ \\
\hline 23 & 0.1786 & $\mathrm{y} / \mathrm{n}$ & $\mathrm{n}$ & 0.8636 & $\mathrm{y} / \mathrm{n}$ & $\mathrm{n}$ & 0.0238 & $\mathrm{y} / \mathrm{n}$ & $\mathrm{n}$ \\
\hline 24 & 0.3564 & $\mathrm{y} / \mathrm{n}$ & $\mathrm{y}$ & 0.9280 & $\mathrm{y} / \mathrm{n}$ & $\mathrm{y}$ & 0.0598 & $\mathrm{y} / \mathrm{n}$ & $\mathrm{y}$ \\
\hline 25 & 0.5512 & $\mathrm{y} / \mathrm{n}$ & y & 0.9638 & $\mathrm{y} / \mathrm{n}$ & $\mathrm{y}$ & 0.1200 & $\mathrm{y} / \mathrm{n}$ & $\mathrm{n}$ \\
\hline 26 & 0.7154 & $\mathrm{y} / \mathrm{n}$ & $\mathrm{y}$ & 0.9550 & $\mathrm{y} / \mathrm{n}$ & $\mathrm{y}$ & 0.2240 & $\mathrm{y} / \mathrm{n}$ & $\mathrm{n}$ \\
\hline 27 & 0.8192 & $\mathrm{y} / \mathrm{n}$ & $\mathrm{y}$ & 0.9140 & $\mathrm{y} / \mathrm{n}$ & $\mathrm{y}$ & 0.2583 & $\mathrm{y} / \mathrm{n}$ & $\mathrm{n}$ \\
\hline 28 & 0.8058 & $\mathrm{y} / \mathrm{n}$ & $\mathrm{y}$ & 0.6636 & $\mathrm{y} / \mathrm{n}$ & $\mathrm{y}$ & 0.0413 & $\mathrm{y} / \mathrm{n}$ & $\mathrm{n}$ \\
\hline 29 & 0 & $\mathrm{n} / \mathrm{n}$ & $\mathrm{n}$ & 0.0136 & $\mathrm{y} / \mathrm{n}$ & $\mathrm{n}$ & 0 & $\mathrm{n} / \mathrm{n}$ & $\mathrm{n}$ \\
\hline 30 & 0 & $\mathrm{n} / \mathrm{n}$ & $\mathrm{n}$ & 0.0282 & $\mathrm{y} / \mathrm{n}$ & $\mathrm{n}$ & 0 & $\mathrm{n} / \mathrm{n}$ & $\mathrm{n}$ \\
\hline 31 & 0 & $\mathrm{n} / \mathrm{n}$ & $\mathrm{n}$ & 0.0254 & $\mathrm{y} / \mathrm{n}$ & $\mathrm{n}$ & 0 & $\mathrm{n} / \mathrm{n}$ & $\mathrm{n}$ \\
\hline 32 & 0 & $\mathrm{n} / \mathrm{n}$ & $\mathrm{n}$ & 0.0282 & $\mathrm{y} / \mathrm{n}$ & $\mathrm{n}$ & 0 & $\mathrm{n} / \mathrm{n}$ & $\mathrm{n}$ \\
\hline 33 & 0.1204 & $\mathrm{y} / \mathrm{n}$ & $\mathrm{n}$ & 0.0294 & $\mathrm{y} / \mathrm{n}$ & $\mathrm{n}$ & 0.00142 & $\mathrm{y} / \mathrm{n}$ & $\mathrm{n}$ \\
\hline 34 & 0.3624 & $\mathrm{y} / \mathrm{n}$ & $\mathrm{n}$ & 0.0296 & $\mathrm{y} / \mathrm{n}$ & $\mathrm{n}$ & 0.0020 & $\mathrm{y} / \mathrm{n}$ & $\mathrm{n}$ \\
\hline 35 & 0.2762 & $\mathrm{y} / \mathrm{n}$ & $\mathrm{n}$ & 0.0062 & $\mathrm{y} / \mathrm{n}$ & $\mathrm{n}$ & 0 & $\mathrm{y} / \mathrm{n}$ & $\mathrm{n}$ \\
\hline 36 & 0.3272 & $\mathrm{y} / \mathrm{n}$ & $\mathrm{n}$ & 0.1440 & $\mathrm{y} / \mathrm{n}$ & $\mathrm{n}$ & 0.00386 & $\mathrm{y} / \mathrm{n}$ & $\mathrm{n}$ \\
\hline 37 & 0.6448 & $\mathrm{y} / \mathrm{n}$ & $\mathrm{y}$ & 0.3168 & $\mathrm{y} / \mathrm{n}$ & $\mathrm{n}$ & 0.05635 & $\mathrm{y} / \mathrm{n}$ & $\mathrm{n}$ \\
\hline 38 & 0.7872 & $\mathrm{y} / \mathrm{n}$ & $\mathrm{y}$ & 0.4484 & $\mathrm{y} / \mathrm{n}$ & $\mathrm{n}$ & 0.05716 & $\mathrm{y} / \mathrm{n}$ & $\mathrm{n}$ \\
\hline 39 & 0.8032 & $\mathrm{y} / \mathrm{n}$ & $\mathrm{n}$ & 0.6256 & $\mathrm{y} / \mathrm{n}$ & $\mathrm{n}$ & 0.06204 & $\mathrm{y} / \mathrm{n}$ & $\mathrm{n}$ \\
\hline 40 & 0.7026 & $\mathrm{y} / \mathrm{n}$ & $\mathrm{n}$ & 0.7890 & $\mathrm{y} / \mathrm{n}$ & $\mathrm{n}$ & 0.04475 & $\mathrm{y} / \mathrm{n}$ & $\mathrm{n}$ \\
\hline 41 & 0.5064 & $\mathrm{y} / \mathrm{n}$ & $\mathrm{n}$ & 0.8728 & $\mathrm{y} / \mathrm{n}$ & $\mathrm{n}$ & 0.03356 & $\mathrm{y} / \mathrm{n}$ & $\mathrm{n}$ \\
\hline 42 & 0.1806 & $\mathrm{y} / \mathrm{n}$ & $\mathrm{n}$ & 0.5834 & $\mathrm{y} / \mathrm{n}$ & $\mathrm{n}$ & 0.00041 & $\mathrm{y} / \mathrm{n}$ & $\mathrm{n}$ \\
\hline 43 & 0 & $\mathrm{n} / \mathrm{n}$ & n 28 & 0.0042 & $\mathrm{y} / \mathrm{n}$ & $\mathrm{n}$ & 0 & $\mathrm{n} / \mathrm{n}$ & $\mathrm{n}$ \\
\hline 44 & 0 & $\mathrm{y} / \mathrm{n}$ & $\mathrm{n}$ & 0.0162 & $\mathrm{y} / \mathrm{n}$ & $\mathrm{n}$ & 0 & $\mathrm{n} / \mathrm{n}$ & $\mathrm{n}$ \\
\hline 45 & 0 & $\mathrm{n} / \mathrm{n}$ & $\mathrm{n}$ & 0.0310 & $\mathrm{y} / \mathrm{n}$ & $\mathrm{n}$ & 0 & $\mathrm{n} / \mathrm{n}$ & $\mathrm{n}$ \\
\hline 46 & 0 & $\mathrm{n} / \mathrm{n}$ & $\mathrm{n}$ & 0.0492 & $\mathrm{y} / \mathrm{n}$ & $\mathrm{n}$ & 0 & $\mathrm{n} / \mathrm{n}$ & $\mathrm{n}$ \\
\hline 47 & 0 & $\mathrm{n} / \mathrm{n}$ & $\mathrm{n}$ & 0.0800 & $\mathrm{y} / \mathrm{n}$ & $\mathrm{n}$ & 0 & $\mathrm{n} / \mathrm{n}$ & $\mathrm{n}$ \\
\hline 48 & 0 & $\mathrm{n} / \mathrm{n}$ & $\mathrm{n}$ & 0.0930 & $\mathrm{y} / \mathrm{n}$ & $\mathrm{n}$ & 0 & $\mathrm{n} / \mathrm{n}$ & $\mathrm{n}$ \\
\hline 49 & 0 & $\mathrm{n} / \mathrm{n}$ & $\mathrm{n}$ & 0.0288 & $\mathrm{y} / \mathrm{n}$ & $\mathrm{n}$ & 0 & $\mathrm{n} / \mathrm{n}$ & $\mathrm{n}$ \\
\hline 50 & 0.0670 & $\mathrm{y} / \mathrm{n}$ & $\mathrm{n}$ & 0.1122 & $\mathrm{y} / \mathrm{n}$ & $\mathrm{n}$ & 0.0006 & $\mathrm{y} / \mathrm{n}$ & $\mathrm{n}$ \\
\hline
\end{tabular}


information levels becomes more important in the analysis of efficient solutions. In the case of unknown values, both the domain approach and the central parameters approach indicate several alternatives as efficient and better than the compromise, which in fact do not dominate the compromise. One of those alternatives is even inefficient. Similarly, when computing the optimal alternative according to the sum of values criterion, many inadequate alternatives would be indicated as possibly optimal for the case of unknown values.

For more detailed results, we refer to [25], where we also show some results concerning the case that no compromise is reached.

\section{Conclusions}

In this paper, we have addressed three ways to deal with incomplete information in the context of negotiations:

1. the extreme parameters approach,

2. the central parameters approach, and

3. the domains approach,

and analyzed how they can be applied to different levels of information that might be available about the preferences of negotiators.

The three methods we have discussed reflect two important trade-offs in dealing with incomplete information. The first trade-off, which can best be illustrated by comparing the extreme parameters approach to the domains approach, can be labeled as ambiguity vs. lack of universality. The domains approach generates only probability statements, which sometimes can be rather vague and might be hard to interpret. This contrasts with the very clear statements generated by the extreme parameters approach. If an alternative is surely better than another alternative according to the extreme parameters approach, there is no doubt how the two alternatives are to be seen, while the domains approach might create statements like there is a 55 percent probability that one alternative $x^{(i)}$ is better than another alternative $x^{(j)}$. However, the advantage of the extreme parameters approach in terms of lower ambiguity comes at a price: the domains approach is able to generate a (probabilistic) statement about any two alternatives, the extreme parameters approach might be unable to state whether one alternative is surely better than the other or vice versa.

The central parameters approach overcomes this dilemma. It will always deliver a unique result, but does so by ignoring much of the information that is available and focusing only on one out of possibly many possible parameter vectors. Thus, it illustrates another important trade-off between information richness and uniqueness of results. Figure 6 illustrates this relationship.

The two dimensions represented in Figure 6 represent trade-offs, both ends of these axes have their advantages and disadvantages. Consequently, there is no method which is clearly better than the others, all methods have their particular strengths and weaknesses, which make them suitable for some tasks. 
Figure 5: Distribution of solutions in utility space
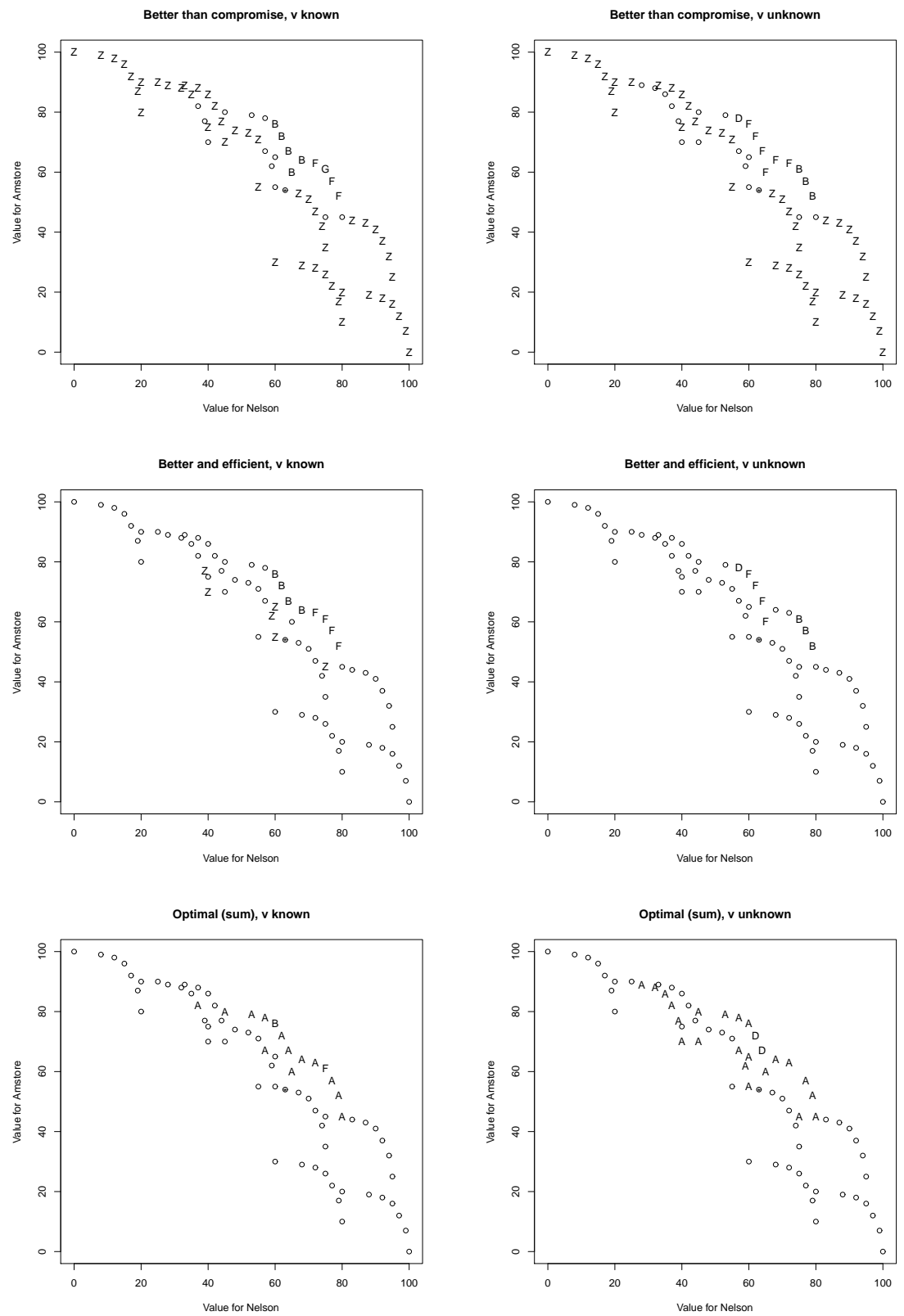

Legend: Property holds...

$\mathrm{Z}=$ Surely not

$\mathrm{D}=$ Only in Central parameter approach

$\mathrm{A}=$ Possibly (computed only for sum)

$\mathrm{B}=$ With $p>0.5$ in Domain approach

$\mathrm{E}=$ Possibly and in Central parameter approach

$\mathrm{C}=$ Surely

$*=$ Proposed compromise

$\mathrm{F}=$ With $p>0.5$ and in Central parameter approach $\mathrm{G}=$ Surely and in Central parameter approach 
Table 6: Summary of solutions obtained

\begin{tabular}{|c|c|c|c|c|}
\hline Concept & Information & Extreme & Central & Domains \\
\hline \multirow[t]{2}{*}{$\begin{array}{l}\text { Comparison } \\
\text { to reference } \\
\text { point in } \\
\text { value space }\end{array}$} & Known values & $\begin{array}{l}\text { Surely: } 39 \\
\text { Surely not: } \\
1-11 \text {, } \\
\text { 15-21, } \\
\text { 29-32, } \\
43-49, \\
51-70\end{array}$ & $38-41$ & $\begin{array}{l}25-28 \\
37-41\end{array}$ \\
\hline & Unknown values & 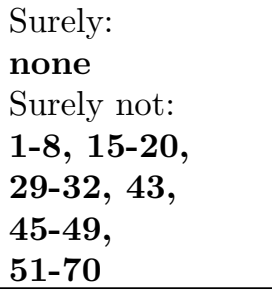 & $\begin{array}{l}24-28 \\
37-38\end{array}$ & $\begin{array}{l}25-28 \\
37-41\end{array}$ \\
\hline \multirow[t]{2}{*}{$\begin{array}{l}\text { Pareto } \\
\text { Efficiency }\end{array}$} & Known values & 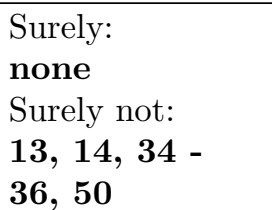 & $38-41$ & $\begin{array}{l}25-26,38- \\
41(1), 27 \\
(0.9724), \\
37(0.5592)\end{array}$ \\
\hline & Unknown values & $\begin{array}{l}\text { Surely: } \\
\text { none } \\
\text { Surely not: } \\
\text { none }\end{array}$ & $24-28$ & $\begin{array}{l}25 \\
(0.9638), \\
26 \\
(0.9550), \\
27 \\
(0.9140), \\
28 \\
(0.6636), \\
39 \\
(0.6256), \\
40 \\
(0.7890), \\
41(0.8728)\end{array}$ \\
\hline \multirow{2}{*}{$\begin{array}{l}\text { Optimal } \\
\text { alternative } \\
\text { using the } \\
\text { sum } \\
\text { criterion }\end{array}$} & Known values & $\begin{array}{l}\text { Surely: } \\
\text { none } \\
\text { Surely not: } \\
\mathbf{1 2}, \mathbf{2 2 - 2 8}, \\
\mathbf{3 3 ,} \mathbf{3 7 - 4 2}\end{array}$ & 39 & $\begin{array}{l}25 \\
(0.5856), \\
39(0.3814)\end{array}$ \\
\hline & Unknown values & $\begin{array}{l}\text { Surely: } \\
\text { none } \\
\text { Surely not: } \\
\mathbf{9 - 1 4} \\
\mathbf{2 1 - 2 8 ,} \\
\mathbf{3 3 - 4 2 , 5 0}\end{array}$ & 24 & $\begin{array}{ll}26 & (0.2240) \\
27 & (0.2583)\end{array}$ \\
\hline Mediator & Known values & alternative 39 & alternative 39 & alternative 39 \\
\hline Recommendat & innknown values & Ndt conclusive & alternative 24 & alt. 26 or 27 \\
\hline
\end{tabular}


Figure 6: Trade-offs between approaches to deal with incomplete information in negotiations.

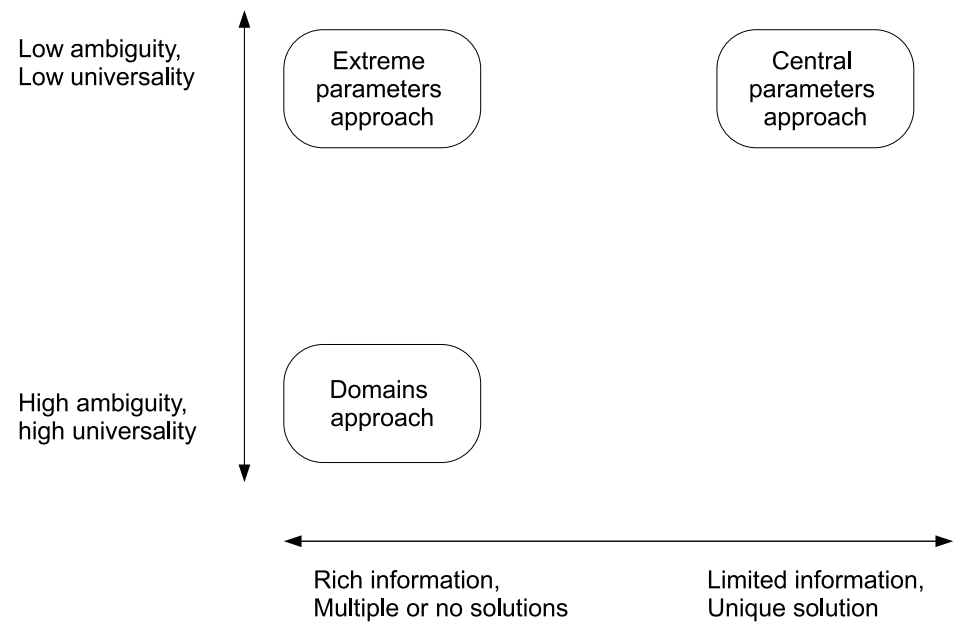

We therefore argue for a mix of methods, which should preferably be implemented in the form of an interactive process. The first step of such a process consists in a pre-selection of alternatives based on the extreme parameters approach. Depending on the purpose of the analysis, further choice between these alternatives can be based on the central parameters approach to obtain specific results, or on the domains approach to better exploit the rich, but potentially ambiguous information available. This integration can probably best be achieved using simulation methods, which make it possible to follow a central parameters approach and a domains approach simultaneously.

While our study has led to some interesting results concerning the advantages and disadvantages of the methods we studied, it also has several limitations which indicate the need for future research. This future research can follow two different directions. The first direction concerns theoretical developments to strengthen the foundations of the methods we have proposed and better delineate the possible areas of application for each method. The second is directed towards implementation and empirical investigation of these methods in a realistic context.

The main focus of our research was on finding solutions which provide a Pareto-improvement over a proposed compromise, or even maximize the total payoff to both negotiators. This kind of improvement is only possible if the 
negotiation problem has some integrative potential at all, in a purely distributive negotiation, no such improvements are possible. It would therefore be important for the negotiators, as well as for a mediator, to know at a very early stage of the negotiation whether such integrative potential exists at all. Of course, even for this purpose, some information on the preferences of negotiators is required. Our research could thus be extended towards identifying the minimal amount of information on preferences that would allow to identify whether the negotiation is integrative at all.

Since our methods rely on information about preferences, the quality of this information is also an important issue. In this paper, we have assumed that all information obtained from negotiators either implicitly or explicitly is consistent and reflects the same true value function of a negotiator. In reality, negotiators might not behave (make offers, accept offers) in a way fully consistent with the model assumptions, or they might provide inconsistent information when explicitly asked about their preferences. It is therefore necessary to extend our methods to deal with such inconsistencies.

Inconsistencies in the responses of negotiators might be the result of an error, but they might also be the result of deliberate manipulation. In particular, when our methods are used by a mediator to suggest potential agreements to negotiators, or even by an arbitrator to calculate a binding solution, there are incentives for parties for strategic misrepresentation of their preferences. While the complexity of the calculations involved would make it difficult for negotiators to manipulate their answers in an optimal way, parties could nevertheless successfully try to improve their situation even by simplistic methods [30]. These possibilities and their impact on the quality of results also need to be analyzed.

While some of these questions can perhaps be answered using analytical methods, the complexity of the relationships will in many cases require computational experiments. In this paper, we have applied our methods only to one single case for illustrative purposes. A thorough analysis of the impact which the choice of different methods, and variants of one method, have on the results requires a larger empirical basis. Such a basis can come from simulation studies with artificial data, but will also require applications of the methods to real data from (experimental) negotiations. Such studies can help to identify conditions under which the different methods lead to different solutions, and to explore how the choice of methods will influence final outcomes.

Apart from these theoretical and empirical developments, further work is needed to foster the practical application of our methods. This includes the development of actual scenarios for their use. While we have discussed the use of the proposed methods mainly as tools for a mediator or arbitrator in the present paper, this is not the only setting in which our proposed methods could be useful: they could also be applied as tools in an asymmetric setting for the support of one party in a negotiation. Of course, in such a setting the quality of information available about the preferences of the two parties will be different, since a negotiator could provide quite exact information about his or her own preferences, but would be restricted to information implicitly obtained from observed behavior concerning the preferences of the opponent. Application of 
our method in such a setting would also require different objective functions to pursue the interests of one party rather than to provide fair solutions in terms of the concepts discussed here. However, the general methodology could also be applied in such a setting.

Eventually, this work should lead to the development of a support system for mediators that helps them in proposing compromise solutions. For an interactive system, computational aspects are also important. We propose the use of Monte Carlo methods, which require the evaluation of many randomly generated parameter vectors. However, we do not foresee problems in embedding this approach into an interactive system for two reasons: First, the problems only require the evaluation of utility function for given parameter values and alternatives, so the total computational load is not that large. Second, since the same operations must be performed for many parameter vectors, the simulation can easily be distributed across several processors to decrease response time.

Embedding the proposed approaches into a user-friendly support system is also a prerequisite for testing the acceptability of the methods by users. There is some empirical evidence that negotiators are reluctant to accept solutions proposed by an automated system, even if it would improve their situation $[13,14]$. Thus it is not clear how negotiators would react to the proposals generated by our methods. This could also be a topic of future empirical research aimed at transforming the theoretical concepts introduced here into practical tools for actual negotiations.

\section{Acknowledgements}

This work benefited from support of FCT / FEDER grant POCI / EGE / 58371 / 2004. P. Sarabando was supported by FCT under grant SFRH / BD / $29178 / 2006$.

\section{References}

[1] F. Barron and B. Barrett. Decision quality using ranked attribute weights. Management Science, 42(11):1515-1523, 1996.

[2] Graldine Bous, Philippe Fortemps, Franois Glineur, and Marc Pirlot. Acuta: A novel method for eliciting additive value functions on the basis of holistic preference statements. European Journal of Operational Research, 206:435444, 2010.

[3] J. Butler, J. Jia, and J.S. Dyer. Simulation techniques for the sensitivity analysis of multi-criteria decision models. European Journal of Operational Research, 103(3):531-546, 1997.

[4] J. Charnetski and R. Soland. Multiple-attribute decision making with partial information: The comparative hypervolume criterion. Naval Research Logistics Quarterly, 25:279-288, 1978. 
[5] J.N. Clímaco and L.C. Dias. An approach to support negotiation processes with imprecise information multicriteria additive models. Group Decision and Negotiation, 15(2):171-184, 2006.

[6] L.C. Dias and J.N. Clímaco. Additive aggregation with variable interdependent parameters: the VIP analysis software. Journal of the Operational Research Society, 51(9):1070-1082, 2000.

[7] L.C. Dias and J.N. Clímaco. Dealing with imprecise information in group multicriteria decisions: A methodology and a GDSS architecture. European Journal of Operational Research, 160:291-307, 2005.

[8] H. Ehtamo, R. Hämäläinen, P. Heiskanen, J. Teich, M. Verkama, and S. Zionts. Generating Pareto solutions in a two-party setting: Constraint proposal methods. Management Science, 45(12):1697-1709, 1999.

[9] S. Greco, V. Mousseau, and R. Slowinski. Ordinal regression revisited: multiple criteria ranking using a set of additive value functions. European Journal of Operational Research, 191(2):415-435, 2008.

[10] P. Heikanen. Decentralized method for computing Pareto solutions in multiparty negotiation. European Journal of Operational Research, 117:578-590, 1999.

[11] E. Jacquet-Lagreze and J. Siskos. Assessing a set of additive utility functions for multicriteria decision-making, the UTA method. European Journal of Operational Research, 10:151-164, 1982.

[12] R. Keeney and H. Raiffa. Decisions with Multiple Objectives: Preferences and Value Tradeoffs. J. Wiley and Sons, New York, 1976.

[13] G.E. Kersten and S.J. Noronha. Rational agents, contract curves, and inefficient compromises. IEEE Transactions on Systems, Man and Cybernetics, 28(3):326-338, 1998.

[14] P. Korhonen, J. Phillips, J. Teich, and J. Wallenius. Are Pareto improvements always preferred by negotiators? Journal of Multi-Criteria Decision Analysis, 7(1):1-2, 1998.

[15] R. Lahdelma, J. Hokkanen, and P. Salminen. SMAA - Stochastic multiobjective acceptability analysis. European Journal of Operational Research, 106(1):137-143, 1998.

[16] R. Lahdelma, K. Miettinen, and P. Salminen. Ordinal criteria in stochastic multicriteria acceptability analysis (SMAA). European Journal of Operational Research, 147(1):117-127, 2003.

[17] G. Lai, C. Li, and K. Sycara. Efficient multi-attribute negotiation with incomplete information. Group Decision and Negotiation, 15:511-528, 2006. 
[18] G Lai and K. Sycara. A generic framework for automated multi-attribute negotiation. Group Decision and Negotiation, 18:169-187, 2009.

[19] J.B. Lasserre. An analytical expression and an algorithm for the volume of a convex polyhedron in $R^{n}$. Journal of Optimization Theory and Application, 39(3):363-377, 1983.

[20] J. Lawrence. Polytope volume computation. Mathematics of Computation, 57:259-271, 1991.

[21] V. Mousseau and L. Dias. Valued outranking relations in Electre providing manageable disaggregation procedures. European Journal of Operational Research, 156(2):467-482, 2004.

[22] D.G. Pruitt. Strategic choice in negotiation. The American Behavioral Scientist, 27(2):167-194, 1983.

[23] H. Raiffa, J. Richardson, and D. Metcalfe. Negotiation analysis: The science and art of collaborative decision making. Belknap Press of Harvard, University Press, Cambridge (Ma), 2002.

[24] P. Sarabando and L. Dias. Comparison of different rules to deal with incomplete information: Perspectives of mediation. Technical report, 2009. Research Reports of INESC Coimbra, No. 2.

[25] P. Sarabando, L. Dias, and R. Vetschera. Approaches to suggest potential agreements: Perspectives of mediation with incomplete information. Technical report, 2009. Research Reports of INESC Coimbra, No. 11.

[26] T. Solymosi and J. Dombi. A method for determining the weights of criteria: the centralized weights. European Journal of Operational Research, 26:35-41, 1986.

[27] M.K. Starr. Product Design and Decision Theory. Prentice Hall, Englewood Cliffs, 1962.

[28] K.W. Thomas. Conflict and conflict management: Reflections and update. Journal of Organizational Behavior, 13:265-274, 1992.

[29] R. Vetschera. A recursive algorithm for volume-based sensitivity analysis of linear decision models. Computers \& OR, 24(5):477-491, 1997.

[30] R. Vetschera. Strategic manipulation of preference information in multicriteria group decision methods. Group Decision and Negotiation, 14:393414, 2005.

[31] R. Vetschera. Learning about preferences in electronic negotiations - a volume based measurement method. European Journal of Operational Research, 194:452-463, 2009. 
[32] D. von Winterfeldt and W. Edwards. Decision Analysis and Behavioral Research. Cambridge University Press, Cambridge, 1986.

[33] R.E. Walton and R.B. McKersie. A Behavioral Theory of Labor Negotiations. McGraw-Hill, New York, 1965.

[34] M. Weber. Decision making with incomplete information. European Journal of Operational Research, 28(1):44-57, 1987. 